\begin{tabular}{|c|l|}
\hline Title & Observations of small - scale disturbances of the Subantarctic Front south of A ustralia \\
\hline Author(s) & A oki, Shigeru; A kitomo, Kazunori \\
\hline Citation & $\begin{array}{l}\text { Deep Sea Research Part I Oceanographic Research Papers, 54(3), 320-339 } \\
\text { https://doi.org/10.1016/.dsr.2006.12.002 }\end{array}$ \\
\hline Issue Date & 2007-03 \\
\hline Doc URL & http://hdl.handle.net/2115/22532 \\
\hline Type & article (author version) \\
\hline File Information & DSR1-54 3.pdf \\
\hline
\end{tabular}

Instructions for use 


\section{Observations of small-scale disturbances of the Subantarctic Front south of Australia}

\section{Shigeru Aoki}

Institute of Low Temperature Science, Hokkaido University, Sapporo

Kazunori Akitomo

Department of Geophysics, Division of Earth and Planetary Science, Kyoto

University, Kyoto

S. Aoki, Institute of Low Temperature Science, Hokkaido University, N19W8, Kita-ku, Sapporo 060-0819, Japan. (e-mail: shigeru@lowtem.hokudai.ac.jp)

K. Akitomo, Department of Geophysics, Division of Earth and Planetary Science, Kyoto University, Kyoto 606-8502, Japan. (e-mail: akitomo@kugi.kyoto-u.ac.jp) 


\section{Abstract.}

High-resolution XCTD and XBT observations were conducted to study eddy variability in the Subantarctic Front (SAF) and its possible impact on the properties of the adjacent Subantarctic Mode Water (SAMW) in the region south of Australia. The stations were occupied along cross-frontal transects in February 2004 and in February and March 2002. Coarse-resolution data from previous WOCE observations were also examined to reveal the water mass properties, including dissolved oxygen (DO). Small-scale (10-20 km) features were detected in the SAF for all high-resolution sections. Fluctuation of the $7{ }^{\circ} \mathrm{C}$ isotherm was clearly revealed at a depth of 300-600 m for the $\sigma_{\theta}=26.8-26.9 \mathrm{~kg} \cdot \mathrm{m}^{-3}$ density range. Temperature and salinity inversions of a similar spatial scale were also found on the same density surface. The spatial scale and depth range of the small-scale anomalies could be consistent with those of the baroclinic instability in the top several hundred-meter layer. In the potential temperature-salinity $(\theta-S)$ diagram, the small-scale fluctuations constitute cold/fresh intrusions from the warm/saline SAMW curve. The intrusions were found on the $\theta-S$ line connecting the deeper SAMW and the shallower Antarctic Surface Water (AASW) of the higher latitudes. From the WOCE observations, the presence of SAMW with high DO was indicated north of the SAF, as previously reported. Within the SAF, intrusions in the $\theta-S$ diagram with relatively high DO were found at around the $7{ }^{\circ} \mathrm{C}$ isotherm for $26.8-26.9 \mathrm{~kg} \cdot \mathrm{m}^{-3}$, the same densities for the small-scale anomalies and the high-DO SAMW. Analysis of heat and salt deficit suggests that the small-scale disturbances have a comparable or larger role than those of meso-scale anomalies. These imply that the small-scale anomalies contribute to the cross-frontal water exchange and to the formation of highDO SAMW. 


\section{Introduction}

The ocean current system in the Southern Hemisphere is characterized by the presence of a strong eastward flow of the Antarctic Circumpolar Current (ACC). The ACC consists of several narrow and persistent fronts, associated with vigorous eddies and meanders (Hofmann, 1985; Orsi et al., 1995). The eddy activities play an important role in the transport and exchange of mass, heat, and momentum. The eddies transport heat polewards to balance the heat loss in the higher polar regimes (de Szoeke and Levine, 1981) and concentrates momentum to the mean flow (Morrow et al., 1994). The Subantarctic Front (SAF) is one of the major fronts of the ACC system. In the Indian Ocean sector, the flow path of the SAF shows a general southward displacement (Orsi et al., 1995; Belkin and Gordon, 1996). Between $40^{\circ}$ and $60^{\circ} \mathrm{E}$, the SAF is merged into the Crozet Front at around $43^{\circ} \mathrm{S}$ (Sparrow et al., 1996; Belkin and Gordon, 1996) and is deflected southward towards the east. After passing the Kerguelen Plateau, the SAF is located at $45-48^{\circ} \mathrm{S}$ between $90^{\circ}$ and $110^{\circ} \mathrm{E}$ and it migrates further southward to $50-53^{\circ} \mathrm{S}$ at $140-150^{\circ} \mathrm{E}$ . In this region it has been observed that the SAF split into "double fronts", separated by $3-5^{\circ}$ in latitude (Belkin and Gordon, 1996; Sokolov and Rintoul, 2002). Progress in satellite instrumentation and the establishment of high-quality hydrographic observations have allowed study of the role of meso-scale $(\sim 100 \mathrm{~km})$ variability of the SAF in detail. For scales shorter than the meso-scale, however, few systematic observations have been made to identify the characteristics and roles of the SAF.

North of the SAF, Subantarctic Mode Water (SAMW) is located in the Southern Ocean. SAMW is basically formed by winter deep convection and ventilates the lower thermocline of the subtropical gyres of the Southern Hemisphere (McCartney, 1977, 1982). The 
properties of the SAMW change at some locations discontinuously. In the Indian Ocean sector of $60-80^{\circ} \mathrm{E}$, a deep SAMW layer with $9{ }^{\circ} \mathrm{C}$ thermostad dominates the layer from a depth of $400-800 \mathrm{~m}$ on the $\sigma_{\theta}=26.75-26.80 \mathrm{~kg} \cdot \mathrm{m}^{-3}$ surface (Piola and Georgi, 1982). The SAMW density gradually increases eastwards along the ACC. Rintoul and England (2002) summarized the temperature-salinity properties south of Australia (about $140^{\circ}$ E ) as the central cluster of $8.8^{\circ} \mathrm{C}, 34.63$ on the $26.85 \mathrm{~kg} \cdot \mathrm{m}^{-3}$ surface with a variable range of $1.5^{\circ} \mathrm{C}, 0.3$. In the southern Tasman Sea at $150-170^{\circ} \mathrm{E}$, the local SAMW with temperature and salinity of $8.5^{\circ} \mathrm{C}, 34.62$ was detected in the slightly denser class of $26.9-27.0 \mathrm{~kg} \cdot \mathrm{m}^{-3}$ (Piola and Georgi, 1982). Winter observations at $145-155^{\circ}$ E captured the formation of deep SAMW with $8.6^{\circ} \mathrm{C}, 34.55$ on the $26.85 \mathrm{~kg} \cdot \mathrm{m}^{-3}$ surface for a layer of 400-500 m in thickness (Thompson and Edwards, 1981). Recent studies using ARGO floats support this transition of the water properties after the Kerguelen Plateau, with cooling, freshening, and densification towards the east (Wong, 2005; Sallée et al., 2006). In addition to these large-scale property changes, Rintoul and Bullister (1999), using winter observations made in 1991, reported that three varieties of SAMW co-existed in the section around $143^{\circ} \mathrm{E}$; cold/fresh $\left(8.8^{\circ} \mathrm{C}, 34.58\right)$, warm/saline $\left(9.5^{\circ} \mathrm{C}, 34.73\right)$, and "intermediate" $\left(9.1^{\circ} \mathrm{C}, 34.66\right)$ modes. To quantify the spatial distribution of these varieties and their interannual and longer-term changes, it is indispensable to understand the differences among the varieties and the formation process of each SAMW.

Although the local air-sea flux is the major factor regulating the SAMW properties, the roles of the cross-frontal transport of the Antarctic Surface Water (AASW) are also considered to be important. A few processes have been proposed to account for the cross-frontal exchange. The SAF roughly coincides with the latitudes of the strongest 
westerly transport, and hence Ekman transport towards the equator, and subsequent vertical mixing can substantially contribute to SAMW formation. Rintoul and Bullister (1999) suggested that the northward Ekman drift of cold/fresh AASW across the front was responsible for the formation of the cold/fresh mode in 1991. Rintoul and England (2002) proposed the dominance of the Ekman component in the interannual variation of SAMW properties based on an order estimation derived from climatological observations, and with their coupled general circulation model (GCM) study. In addition to Ekman transport, the role of eddies on various scales has also been indicated. Sallée et al. (2006) used strong eddy mixing in a heat budget of the SAMW in the South Indian Ocean from $40^{\circ}$ to $80^{\circ} \mathrm{E}$. For the region south of Australia, Morrow et al. (2004) showed that coldcore rings, detached from meanders of the SAF, supply an "old" SAMW. The cold-core eddies can contribute a heat deficit of $-3.8 \times 10^{19} \mathrm{~J} \cdot \mathrm{yr}^{-1}$ and a salt deficit of $-1.6 \times 10^{12}$ $\mathrm{kg} \cdot \mathrm{yr}^{-1}$, with the salt deficit comparable to that induced by Ekman transport. Eddy variability is hence one of the contributors to heat and freshwater exchange across the SAF and mode water formation. However, the exchange process by smaller-scale eddies and their impact on mode water formation are poorly understood.

To investigate small-scale structure in the SAF and its possible impact on the adjacent SAMW properties, spatially dense XCTD/XBT observations were conducted south of Australia. The Blue Earth Global Expedition 2003 (BEAGLE2003) and the 43rd Japanese Antarctic Research Expedition (JARE43) provided opportunities for the highresolution measurements near $105^{\circ}$ and $140^{\circ}$ E (Fig. 1). South of Australia, high-quality World Ocean Circulation Experiment (WOCE) observations were made across the SAF along I8, I9 and SR3 sections in the 1990s. To further describe the properties of varieties 
of the SAMW, previous WOCE observations along I8 and SR3 were reexamined. These hydrographic sections have a spatial resolution of $0.25-0.5^{\circ}$. This spacing does not resolve the smaller-scale variations, but these data can provide high-quality observations of temperature and salinity, together with information on other tracer concentrations with bottle sampling. The water properties derived from these observations were then compared to investigate the influence of small-scale anomalies and any possible relationship with the formation of SAMW varieties.

\section{Data sources}

High-resolution XCTD/XBT observations were conducted across the SAF to directly capture its small-scale structure. In addition to the XCTD/XBT observations, previous WOCE CTDs and bottle data were used to examine the SAF and SAMW properties in detail. Here we describe these hydrographic data and other supporting material.

\subsection{High-resolution XCTD and XBT observations with BEAGLE2003 and}

\section{JARE43}

High-resolution XCTD and XBT observations were made along two sections (Fig. 1). Observation in the western region (near $105^{\circ} \mathrm{E}$ ) was conducted as part of the BEAGLE2003 expedition in February 2004, and the observations in the eastern region (along the $140^{\circ}$ E line) were part of JARE43 in February-March 2002.

BEAGLE2003 observations were made near $105^{\circ} \mathrm{E}$ by the R/V Mirai on 14 February 2004. A Tsurumi Seiki XCTD/XBT system was used. XCTD and T-7 XBT probes were deployed with a ship-equipped auto-launcher, and MK-100 and MK-30N digital converters were used to retrieve the data. For most of the region of intensive observation from $46^{\circ}$ $30^{\prime} \mathrm{S}, 103^{\circ} 30^{\prime} \mathrm{E}$ to $45^{\circ} 20^{\prime} \mathrm{S}, 106^{\circ} 18^{\prime} \mathrm{E}$, XBT and XCTD were deployed every $0.5^{\prime}$ 
in latitude (roughly corresponds to $2 \mathrm{~km}$ in actual displacement). Outside the intensive region, XCTD was conducted at a latitudinal interval of $0.5^{\circ}$. The $\mathrm{R} / \mathrm{V}$ Mirai is equipped with Doppler sonar for monitoring the surface current, and the data were also used to support the location of the front.

The JARE43 observations were conducted along $140^{\circ} \mathrm{E}$ by the $\mathrm{R} / \mathrm{V}$ Tangaroa. A Tsurumi Seiki XCTD/XBT system was also used in this operation. The XCTD, T-6 (for the southbound leg on 9 February) and T-7 (for the northbound leg on 3 March) XBT probes were used, and an MK-130 digital converter was used to retrieve the data. In the region of intensive observation from $50^{\circ} 04^{\prime} \mathrm{S}$ to $50^{\circ} 46^{\prime} \mathrm{S}$ (southbound) and from $50^{\circ} 00^{\prime} \mathrm{S}$ to $51^{\circ} 03^{\prime} \mathrm{S}$ (northbound), XBTs were deployed at intervals of approximately $2 \mathrm{~km}$. XCTDs were deployed at a $0.5^{\circ}$ interval during the southbound leg and at a $0.25^{\circ}$ interval during the northbound leg. Hence, the interval of the salinity sampling in JARE43 transects was much sparser compared to that in the BEAGLE2003 section. Outside the region of intensive survey, XCTDs were routinely deployed at every $0.5^{\circ}$ in latitude.

XCTD measurements were less accurate compared to CTD observations. According to a direct comparison between XCTD and CTD in this ocean sector, temperature accuracy was estimated to be better than $0.03{ }^{\circ} \mathrm{C}$ down to $1000 \mathrm{~m}$, although the estimation was derived with only two probes (Aoki and Sato, 2004). This temperature error is not critical in the present study. For salinity, however, the depth-averaged error amounted to 0.036 for one cast at $54^{\circ} \mathrm{S}$. The salinity error mainly consisted of a drift component $\left(1.2 \times 10^{-4}\right.$ $\mathrm{m}^{-1}$ ). Additional validation with CTD for the Antarctic waters supported the offset of around 0.04 deeper than $300 \mathrm{~m}$ (Aoki, 2006), but the error does not have fluctuations whose scales are from several tens to a few hundreds of meters. Thus, large-amplitude 
signals, that are continuous for several tens to a hundred of meters, can generally be perceived as natural, provided that the absolute salinity may be subjected to the offset.

\subsection{WOCE observations}

Hydrographic data for WOCE sections across the SAF were also used to provide highly accurate temperature, salinity, and dissolved oxygen (DO) profiles and to compare them with the high-resolution XCTD/XBT observations.

WOCE I8 line was conducted along 95 E in December 1994-January 1995. CTD/Rosette Multi-Sampler (RMS) observations near the SAF at $43-45^{\circ} \mathrm{S}$ were made on 7-9 January. The sampling interval was about $0.25^{\circ}$.

WOCE SR3 observations were repeatedly made across the SAF near $143^{\circ} \mathrm{E}$, and the CTD/RMS data for 8-16 October 1991, 14-16 March 1993, and 4-8 January 1994 were used for the present study. The spatial resolution was roughly $0.5^{\circ}$ in latitude.

2-dbar CTD data were used for the analysis. The DO data derived from bottle samplings were used to describe the water mass characteristics.

\subsection{Satellite altimetry}

Altimetric observations of the sea surface height were used to investigate the mesoscale background features. AVISO Absolute Dynamic Topography (ADT) and Sea Level Anomaly (SLA) products were used; the ADT is the sum of the mean field derived from a combination of hydrography and GCM, and the SLA field is derived from satellite altimetry (Rio and Hernandez, 2004). The data are provided on a weekly basis, and the maps nearest to the observation date are shown. 


\section{Small-scale disturbances in the SAF}

The high-resolution XCTD/XBT observations can resolve the detailed structure of the SAF in the western and eastern regions south of Australia. Observed small-scale features of the SAF are described here with their background meso-scale structures.

\subsection{Meso-scale background fields for high-resolution observations}

a) The western region near $105^{\circ} \mathrm{E}$

The BEAGLE2003 leg traversed the SAF obliquely at $46^{\circ} \mathrm{S}$ near $105^{\circ} \mathrm{E}$ (Fig. 2). The transect cut the southeastern flank of an anti-cyclonic meander or warm-core eddy of $100-\mathrm{km}$ scale, centered at $46^{\circ} \mathrm{S}$ and $104^{\circ} \mathrm{E}$, and crossed the SAF again near $45.5^{\circ} \mathrm{S}$ and $106^{\circ} \mathrm{E}$. The high-resolution observations were conducted in the ADT range from 1.4 to $1.6 \mathrm{~m}$ (above the geoid height). The meandering flow structure was also clearly revealed by ship-board surface velocity data. The velocity vector was eastward near $103^{\circ}$ $\mathrm{E}$, northward near $105^{\circ} \mathrm{E}$, and then southeastward near $106^{\circ} \mathrm{E}$. The maximum speed at the surface was in excess of $0.5 \mathrm{~m} / \mathrm{s}$.

In the vertical profiles of temperature and salinity, a warm/saline intrusion was detected near $46^{\circ} \mathrm{S}$, associated with the anti-cyclonic meander/eddy (Fig. 3a and b). The location of the intrusion coincided well with that derived from altimetry. A thermostad (halostad) of $9-10.5^{\circ} \mathrm{C}(34.6-34.85)$ was found below the surface seasonal mixed-layer and above 400 $m$ depth inside the meandering core and to the north of the SAF, indicating the presence of an SAMW layer. Density was in the range of $26.7-26.9 \mathrm{~kg} \cdot \mathrm{m}^{-3}$ (Fig. 3c). To the north of the SAF, an SAMW layer of the same temperature-salinity properties existed. Potential vorticity was low $\left(\sim 20 \mathrm{PVU} ; 1 \mathrm{PVU}=10^{-14} \mathrm{~cm}^{-1} \cdot \mathrm{s}^{-1}\right)$ for the layer above a 
depth of 400-500 m, and still relatively low ( 20 PVU) for the layer down to $600-700 \mathrm{~m}$ (Fig. $3 \mathrm{~d}$ ).

b) The eastern region near $140^{\circ} \mathrm{E}$

The JARE43 observations were conducted in the SAF along $140^{\circ} \mathrm{E}$. The SAF axis was located at $50.3^{\circ} \mathrm{S}$ on 9 February and at $50.5^{\circ} \mathrm{S}$ on 3 March, and it showed a southward shift of 20-30 km for this 3-week period along this section. From the ADT distributions on 13 February and 6 March, the high-resolution observations covered the ADT range from 1.0 to $1.6 \mathrm{~m}$ (Fig. 4a and b). The SLA fields showed that the same positive anomaly migrated southeastward and the sections sampled the same anomaly with different locations relative to the center of the anomaly (Fig. 4c and d). To the north of the SAF, a thermostad (halostad) of $8-9.5^{\circ} \mathrm{C}(34.55-34.70)$ was found on $26.75-26.85 \mathrm{~kg} \cdot \mathrm{m}^{-3}$ surfaces at a depth of 200-500 m (Fig. 5). The potential vorticity was relatively low ( 60 PVU) down to a depth of $700 \mathrm{~m}$. The frontal positions in the temperature and salinity profiles coincided well with those derived from the ADT distributions.

\subsection{Small-scale disturbances in the SAF}

a) The western region near $105^{\circ} \mathrm{E}$

High-resolution XCTD/XBT observations were conducted across the SAF. The observed temperature field revealed small-scale disturbances in the frontal region, together with a meso-scale variation (Fig. 6). General shoalings of isotherms between depths of 600-700 to $100 \mathrm{~m}$ were found at $46.2-46.4^{\circ}$ and $45.6-45.8^{\circ} \mathrm{S}$ on the edges of the anti-cyclonic meander or warm core eddy, and at $45.3-45.5^{\circ} \mathrm{S}$ on the SAF axis. The inclination at depths deeper than $400 \mathrm{~m}$ was $3-7 \times 10^{-3}$. At the edge of the meander and in the adjacent region, several small-scale disturbances of 10-20-km scale were detected. 
At the northeastern edge of the anti-cyclonic meander/eddy at stations 32-33 of the $\mathrm{XCTD}$ casts $\left(45.6-45.7^{\circ} \mathrm{S}\right)$, there was a distinct fluctuation of the $7^{\circ} \mathrm{C}$ isotherm (Anomaly B1), which consisted of a downward (from 400 to $600 \mathrm{~m}$ ) warm anomaly from outside of the meander and an upward (from 600 to $100 \mathrm{~m}$ ) cold anomaly from its inside. At station $33\left(45.62^{\circ} \mathrm{S}\right)$, a relatively cold/fresh anomaly was detected just below the seasonal mixedlayer, while a warm/saline anomaly was found at 450-500 m (Figs. 6 and $7 \mathrm{a}$ and b). At station $32\left(45.65^{\circ} \mathrm{S}\right)$, a relatively warm/saline disturbance was observed at around $550 \mathrm{~m}$ of a slightly higher density $\left(\sim 27.0 \mathrm{~kg} \cdot \mathrm{m}^{-3}\right)$ surface (Fig. $\left.7 \mathrm{c}\right)$, while a cold/fresh anomaly was detected just above the warm/saline anomaly. The inclination of isotherms in the small-scale disturbance was steeper $\left(\sim 20 \times 10^{-3}\right)$ than that of the meso-scale background isotherms. At $45.8-45.9^{\circ} \mathrm{S}$, inside the meander and $20-30 \mathrm{~km}$ away from the frontal edge, a salinity inversion and a fluctuation of isotherms (Anomaly B2) were detected on the $26.85-26.9 \mathrm{~kg} \cdot \mathrm{m}^{-3}$ surface at a depth of 400-500 m (Fig. 7b). The spatial scale of this anomaly was again $10-20 \mathrm{~km}$. This feature was in almost the same temperature and salinity ranges as those of Anomaly B1. The variable ranges of salinity and temperature were $0.1-0.2$ and $\sim 1{ }^{\circ} \mathrm{C}$, and the variation showed a tendency to density compensation.

At the southern flank of the meander near station $7\left(46.4-46.5^{\circ} \mathrm{S}\right)$, temperature inversions (Anomaly B3) were detected around the $7{ }^{\circ} \mathrm{C}$ isotherm at a depth of 300-400 m (Fig. 6). Slightly inside of the meander at station $10\left(46.2^{\circ} \mathrm{S}\right)$ and station $13\left(46.3^{\circ}\right.$ $\mathrm{S}$ ), fluctuations of the $7.5^{\circ} \mathrm{C}$ isotherm by $100 \mathrm{~m}$ (Anomalies B4 and B5) were centered at a depth of 400-600 m. A salinity disturbance was also detected for station 10 (Fig. $7 \mathrm{~b})$. The temperature in this layer was in the range $7-8{ }^{\circ} \mathrm{C}$, and salinity was in the range 34.45-34.6. A similar fluctuation was also detected at the SAF axis at $45.4^{\circ} \mathrm{S}$. 
These observations, in addition to the anomalies on the northeastern flank, suggest the ubiquitous presence of small-scale disturbances along the axis of the SAF.

Potential temperature-salinity $(\theta-S)$ diagrams exhibit a transition between the cold/fresh regime of higher latitudes and the warm/saline regime of lower latitudes across the SAF and reveal highly variable properties in the core of the SAF (Fig. 8). At the southern flank of the meander (Fig. 8a), the temperature-salinity properties in the salinity inversion layer at a depth around $400 \mathrm{~m}$ (stations 6-13; cyan, green and red dots) were almost on the line that connects the shallower AASW at the higher latitudes (at $200 \mathrm{~m}$ at stations 1-5; blue squares) and the deeper SAMW at the lower latitudes (at $400 \mathrm{~m}$ at stations 14-18; black dots). The water in the salinity inversion at $500 \mathrm{~m}$ at station 13 (red triangle) formed an intrusion to the cooler/fresher side from the warm/saline line. The temperature-salinity property in the intrusion was close to that of the 400 -m water of the stations at the southern flank (stations 6-8; cyan dots). At the northeastern flank near $45.5^{\circ} \mathrm{S}$, a similar regime transition is shown in Fig. $8 \mathrm{~b}$. The water in the small-scale disturbance at $400 \mathrm{~m}$ (stations 33-34; red dots) formed intrusions into the cooler/fresher side. The intrusions had intermediate temperature-salinity properties that were on the line connecting the SAMW and AASW, as was found for the southern flank of the meander. Thus, these intrusions represent a typical feature of the small-scale anomalies and they can most simply be explained as a isopycnal mixing process between the shallow, cold/fresh AASW at the higher latitudes and deep, saline/warm SAMW at the lower latitudes.

b) The eastern region near $140^{\circ} \mathrm{E}$ 
Small-scale disturbances were also detected in the SAF region along $140^{\circ} \mathrm{E}$. The XBT temperature profile on 9 February, 2002 shows a small-scale disturbance (Anomaly J1) of 20-km scale at $50.2-50.4^{\circ} \mathrm{S}$ down to a depth of $400 \mathrm{~m}$ (Fig. 9a). Undulation of the 6-7 ${ }^{\circ} \mathrm{C}$ isotherms was clearly revealed from depths of 400 to $100 \mathrm{~m}$; a warm anomaly, inclined equatorward with depth, was detected at 50.3-50.4 $\mathrm{S}$ and a cold anomaly, tilted in the same direction, was identified at $50.2-50.3^{\circ} \mathrm{S}$. There was no observation deeper than 460 $\mathrm{m}$ for this section owing to probe length limitations.

The XCTD/XBT temperature profile on 3 March again exhibits a small-scale disturbance (Anomaly J2) of $20-\mathrm{km}$ scale at $50.4-50.6^{\circ} \mathrm{S}$ down to $400-500 \mathrm{~m}$ (Fig. 9b). The isotherms revealed a similar disturbance in the range from 6 to $8^{\circ} \mathrm{C}$. A cold core was detected at around $400 \mathrm{~m}$ at $50.45^{\circ} \mathrm{S}$ and the cold feature was traced up to $100 \mathrm{~m}$, showing an equatorward tilt with increasing depth. A warm feature was visible down to a depth of $300 \mathrm{~m}$ at $50.55^{\circ} \mathrm{S}$ to the poleward side of the cold anomaly. The density of this level was estimated to be $26.85-27.0 \mathrm{~kg} \cdot \mathrm{m}^{-3}$ from the adjacent XCTD observations. The inclination of the isotherms in this disturbance was an order of magnitude steeper above 500 $\mathrm{m}\left(50-70 \times 10^{-3}\right)$ than the general slopes below this depth $\left(\sim 5 \times 10^{-3}\right)$. Near $50.8-50.9^{\circ} \mathrm{S}$ slightly south of this area, there were also disturbances of $4.5-5{ }^{\circ} \mathrm{C}$ isotherms (Anomaly J3) on a similar spatial scale. The southern branch of the SAF is climatologically located at $52-53^{\circ} \mathrm{S}$ in this region (Sokolov and Rintoul, 2002), and the disturbances were hence in the SAF zone based on its temperature criteria. Thus, the presence of small-scale disturbances was confirmed to be a repeating feature in the SAF region near $140^{\circ} \mathrm{E}$. 


\section{Presence of a high-oxygen variety of SAMW}

A thermostad and halostad of the SAMW are located to the north of the SAF, and the presence of SAMW varieties has been reported. To reveal detailed features of these SAMW varieties, the water mass properties near the SAF were examined.

a) The western region (WOCE I8 section)

In December 1994, WOCE I8 observations were conducted along 95 E . The SAF was located at $43-44^{\circ} \mathrm{S}$, with a meander at $45^{\circ} \mathrm{S}$ (Fig. 10). To the north of the SAF, the SAMW layer of $9.5-11^{\circ} \mathrm{C}, 34.65-34.9$ on the $26.7-26.8 \mathrm{~kg} \cdot \mathrm{m}^{-3}$ surface was found down to 300-400 dbar below the seasonal mixed-layer. At station 29, the potential temperature and salinity were slightly lower in the layer at 500-600 dbar than in those above, while the density was relatively homogeneous down to this layer. There was a slight intrusion in the $\theta-S$ curve (red triangle) at around 540 dbar, with potential temperature and salinity of $8.5^{\circ} \mathrm{C}$ and 34.6 (Fig. 11a). Immediately poleward at stations 30 and 31 in the SAF, the intrusions were larger and clearer (cyan and green dots), and their depth levels were located at around 400 dbar. The waters of these intrusions were almost of the same density of $26.87 \mathrm{~kg} \cdot \mathrm{m}^{-3}$. In the front and meandering regions from stations $32-36$, many intrusions appeared at shallower depths at around 200 dbar (blue squares). The shallow AASW (150-250 dbar) below the seasonal mixed-layer had high DO from 280 to 295 $\mu \mathrm{mol} \cdot \mathrm{kg}^{-1}$ (Fig. 11b). The water of relatively high DO $\left(260 \mu \mathrm{mol} \cdot \mathrm{kg}^{-1}\right)$ at $498 \mathrm{dbar}$ at station 29 was approximately on the $\theta-$ DO line connecting the subsurface AASW with water of high DO $\left(280-290 \mu \mathrm{mol} \cdot \mathrm{kg}^{-1}\right)$ and SAMW with water of relatively low DO (250 $\left.\mu \mathrm{mol} \cdot \mathrm{kg}^{-1}\right)$. Thus, the high-DO water can most simply be explained by mixing between the deeper SAMW (several hundred meters) and shallower AASW (around 200 dbar). 
b) The eastern region (WOCE SR3 section)

For the SR3 section, "intermediate" variety of SAMW with relatively high DO (low apparent oxygen utilization) was found at a depth of $400-500$ dbar at $49^{\circ} \mathrm{S}$ in October 1991 (Rintoul and Bullister, 1999; typically shown at station 7 in Fig. 12a). The "intermediate" mode had a potential temperature (salinity) of $9.1{ }^{\circ} \mathrm{C}(34.66)$, while that of the warm/saline mode (typically shown at a depth of 0-400 dbar at stations 4-5) was 9.5 ${ }^{\circ} \mathrm{C}(34.73)$ and that of the cold/fresh mode (typically shown at a depth of 0-300 dbar at station 7 ) was $8.8^{\circ} \mathrm{C}(34.58)$ (Fig. 13a). The DO of the "intermediate" mode was lower by only $5 \mu \mathrm{mol} \cdot \mathrm{kg}^{-1}$ than that of the cold $/$ fresh mode water, which was thought to be generated by mixing in the winter (Fig. 12a).

In addition to the section in 1991, relatively high-DO waters were detected for other observations as well. In March 1993, the SAF was centered at 50.5 S (Fig. 12b). SAMW of $9.0-9.5^{\circ} \mathrm{C}$ was found to the north of the SAF. At station $15\left(49.8^{\circ} \mathrm{S}\right)$, at the equatorward edge of the front, a relatively high-DO layer of $260 \mu \mathrm{mol} \cdot \mathrm{kg}^{-1}$ was found at $300-600$ dbar, opposing the general decreasing trend towards deeper levels (Fig. 12b, right panel). The potential temperature (salinity) of the high-DO layer was $8.8^{\circ} \mathrm{C}(34.6)$, with slightly cooler and fresher property than the layer above, and the density was $26.85 \mathrm{~kg} \cdot \mathrm{m}^{-3}$. This property is close to that of the central cluster of the SAMW in this region (Rintoul and England, 2002). The base of the high-DO layer showed an intrusion (red triangle) at 610 dbar in the $\theta-S$ diagram (Fig. 13c). At station 16, a similar intrusion was found at a slightly shallower level of 480 dbar (green triangle). From the $\theta$-DO diagram, DO values of around $260 \mu \mathrm{mol} \cdot \mathrm{kg}^{-1}$ at $500 \mathrm{dbar}$ at stations 15 and 16 were roughly on the 
line between the SAMW and shallower AASW at around 200 dbar at stations 17 and 18 (Fig. 13d).

In January 1994, the SAF was centered at $50.5^{\circ} \mathrm{S}$, and a cold-core ring was located at $48-49^{\circ} \mathrm{S}$ (Phillips and Rintoul, 2000; shown in Fig. 12c). SAMW of around $9{ }^{\circ} \mathrm{C}$ was found to the north of the SAF. At station $22\left(49.8^{\circ} \mathrm{S}\right)$ at the center of the meander, there was an SAMW layer at a depth of $400-600$ dbar with DO higher by $5 \mu \mathrm{mol} \cdot \mathrm{kg}^{-1}$ than the layer above (Fig. 12c, right panel). The potential temperature and salinity of the high-DO layer were $8.85^{\circ} \mathrm{C}$ and 34.62 , which were nearly the same as the above central cluster of SAMW (Fig. 13e). Intrusions to the cold/fresh side were found at station 19 at 520 dbar (magenta triangle). The $\theta-$ DO diagram shows that the DO at around 200 dbar at station 24 was $260 \mu \mathrm{mol} \cdot \mathrm{kg}^{-1}$ and it increased to $290 \mu \mathrm{mol} \cdot \mathrm{kg}^{-1}$ at the same depth at station 26 (Fig. 13f). These points were nearly on the line between the SAMW and AASW properties.

Thus, it was confirmed that the subsurface high-DO feature below the well-mixed layer was not fortuitous just north of the SAF. The temperature and salinity of the high-DO SAMW in March 1993 and January 1994 were both near the central cluster of $8.8^{\circ} \mathrm{C}$ , 34.63. On the same density range, intrusions of high-DO water were observed to the poleward side of the SAF. The property of the high-DO waters was on the line between the SAMW and the shallower AASW at the higher latitudes.

\section{Discussion}

Small-scale anomalies were detected for all three high-resolution XCTD/XBT sections of BEAGLE2003 and JARE43. A high-DO layer was also found at a depth of 400$600 \mathrm{~m}$ to the north of the SAF core for the WOCE sections. Here we examine the 
possible relationship between the small-scale disturbances and high-DO SAMW and infer a mechanism for these anomalies.

\subsection{Consistency of the SAF and SAMW properties with those of previous observations}

The SAF in the western region was found near $44-46^{\circ} \mathrm{S}$. This location is consistent with previous studies (Hoffmann, 1985; Nagata et al., 1988; Belkin and Gordon, 1996; Yuan et al., 2004). The SAF in the eastern region was detected near $50^{\circ} \mathrm{S}$. This latitudinal band corresponded to the northern branch of the SAF (Sokolov and Rintoul, 2002), which is one of the "double" SAF structures in this sector. The SAF shows a general southward migration from west to east, south of Australia. The overall southward shift of the SAF is consistent with Belkin and Gordon's (1996) study. This migration is probably controlled by the bathymetric feature (conservation of potential vorticity) of the Southeast Indian Ridge (Hofmann, 1985).

Generally, the SAMW was cooler and fresher in the eastern region than in the western region. The temperature observed was in the range $10-11{ }^{\circ} \mathrm{C}$ at $95^{\circ} \mathrm{E}, 9-10{ }^{\circ} \mathrm{C}$ at $105^{\circ} \mathrm{E}$, and $8-9.5^{\circ} \mathrm{C}$ at $140^{\circ} \mathrm{E}$. The salinity was $34.65-34.85$ at $95^{\circ} \mathrm{E}, 34.6-34.85$ at $105^{\circ} \mathrm{E}$, and 34.55-34.70 at $140^{\circ} \mathrm{E}$. This tendency is also consistent with previous studies (Piola and Georgi, 1982; Belkin and Gordon, 1996; Sallée et al., 2006). Thus, the background flow and water mass structures in the 1990s and early 2000s were normal over the observation periods, so significant temporal changes in SAMW formation mechanisms are unlikely.

\subsection{Small-scale anomalies and high-DO SAMW}

The small-scale anomalies showed steeper inclination of isotherms than those of the background meso-scale structure. Fluctuations in the vertical plane could be recognized 
as tilting poleward with depth for Anomaly B1 in Fig. 6 and equatorward with depth for Anomalies J1 and J2 in Fig. 9. These are, however, in the same direction in the frontal coordinate perpendicular to the flow direction. Warm/saline anomalies were found to the "higher" latitudes in the frontal coordinate, while cold/fresh anomalies were detected to the "lower" latitudes. This structure could be consistent with poleward heat and equatorward freshwater transfer, suggesting a possible role in meridional exchange by the small-scale fluctuations. The fact that a similar feature was observed in both western and eastern regions strongly suggests that it is a common structure of the SAF throughout this ocean sector.

For the northeastern flank of the meander in the BEAGLE2003 transect (around Anomaly B1), the density profile showed equatorward shoaling from the meandering warm core near station 20 (at $46^{\circ} \mathrm{S}$ ) to the center of the cold intrusion at station $36\left(45.5^{\circ}\right.$ S ). However, the density surfaces between 26.8 and $27.0 \mathrm{~kg} \cdot \mathrm{m}^{-3}$ were slightly deeper at station $35\left(45.55^{\circ} \mathrm{S}\right)$ and shallower at station $33\left(45.62^{\circ} \mathrm{S}\right)$, opposing the general shoaling trend from station 30 to station 36 . The vertical density gradient was relatively downward intensified at station 35 down to about $700 \mathrm{~m}$ compared with that at station 33. This small-scale density fluctuation was almost cancelled at levels deeper than about $700 \mathrm{~m}$. This may be a result of vertical motion due to an ageostrophic component across the front (Pollard and Regier, 1992).

From the high-resolution XCTD/XBT sections, intrusions in the $\theta-S$ diagrams were detected for the small-scale disturbances at a depth of 300-600 m. From the WHP observations, a high-DO mode was found at a depth of 400-600 m north of the SAF, and, immediately poleward of the SAF core, intrusions of almost the same temperature and 
salinity range were detected. It is most likely that the intrusions in the WOCE observations were parts of the small-scale disturbances that were sampled inadequately on a spatial scale. It was also revealed that the waters in the intrusions were relatively rich in DO. A high-DO mode of SAMW was found on a line of nearly equal density connecting the SAMW and the intrusions, and where the intrusions are absorbed into the homogeneous SAMW. Hence, we propose that the high-DO mode was generated by isopycnal mixing between the SAMW and shallower AASW at the higher latitudes, which was the consequence of the small-scale disturbances in the SAF axis.

\subsection{Possible mechanism and impact of the small-scale anomalies}

The observed small-scale features were on a scale of 10-20 km and centered at a depth of $300-600 \mathrm{~m}$. This spatial scale and depth range could be consistent with those of the baroclinic instability in the top several hundred-meter layer. To test the necessary condition for baroclinic instability, $Q_{y}$ (Gill et al., 1974) was approximately estimated, given by:

$$
Q_{y}=\beta+f\left(\frac{\rho_{y}}{\rho_{z}}\right)_{z}
$$

where $f$ and $\beta$ are the Coriolis parameter and its meridional gradient, and $\rho$ is the density of the mean field. Because there are no mean density data available in this study, the density observation for BEAGLE2003 was used instead. The density field observed was fairly unstable for vertical gradients of higher order, and hence polynomial line-fitting was applied before the vertical gradient of the second term was calculated. Reasonably stable results were obtained for three regimes at $49^{\circ} \mathrm{S}$ (south of the SAF), $45.6^{\circ} \mathrm{S}$ (in the $\mathrm{SAF}$ ), and $42^{\circ} \mathrm{S}$ (north of the SAF; Fig. 14). In the SAF, the $Q_{y}$ profile showed large fluctuations, but the profiles away from the front were relatively stable. $Q_{y}$ in the SAF 
showed a change in sign at a level of $100 \mathrm{~m}$, which may reflect instability in the top layer. There were also changes in sign at levels of 400 and $700 \mathrm{~m}$. Phillips and Rintoul (2002) used mooring data across the SAF along SR3 and showed that the condition necessary for baroclinic instability was met in the depth range of $560 \mathrm{~m}$. A simple two-layer model (Phillips, 1954) with an upper layer $\left(\sigma_{\theta}=26.7 \mathrm{~kg} \cdot \mathrm{m}^{-3}\right)$ and a lower layer $\left(\sigma_{\theta}=26.9\right.$ $\mathrm{kg} \cdot \mathrm{m}^{-3}$ ) of $300 \mathrm{~m}$ in thickness can give wavelengths of approximately $20 \mathrm{~km}$, which is nearly the same scale as for the observed anomalies. Numerical studies with almost the same setting $\left(0.1 \mathrm{~kg} \cdot \mathrm{m}^{-3}\right.$ stratification for basin of $1000 \mathrm{~m}$ in depth) revealed variability on a similar scale (Yoshikawa et al., 2001). Thus, it is suggested that these small-scale features are essentially caused by baroclinic instability in this top layer of several hundreds of meters, although further robust evidence is needed to support this idea.

The adjacent setting of warm/saline and cool/fresh waters may also be favorable for thermohaline interleaving. At some stations north of the SAF, temperature profiles in the SAMW showed a step-like feature on a scale of a few tens of meters. However, the distinct small-scale anomalies had a vertical scale of $100 \mathrm{~m}$, which is slightly greater than the typical scales for interleaving (Ruddick, 1992). Further analysis is needed to fully assess the influence of thermohaline interleaving.

To estimate the roles and impacts of the small-scale anomalies on meridional heat and freshwater transport, the available heat anomaly (AHA) and available salinity anomaly (ASA) (Joyce et al., 1981; Morrow et al., 2004) on the potential density surface were calculated according to the following formula;

$$
\begin{aligned}
A H A & =\rho_{i} c_{p} h_{i}(r)\left[T_{\sigma}(r)-T_{\sigma}(\text { ref })\right], \\
A S A & =0.001 \rho_{i} h_{i}(r)\left[S_{\sigma}(r)-S_{\sigma}(\text { ref })\right],
\end{aligned}
$$


where $\rho_{i}$ is the vertically averaged density (in $\mathrm{kg} \cdot \mathrm{m}^{-3}$ ), $c_{p}$ is the specific heat capacity (in $\left.J \cdot \mathrm{kg}^{-1} \cdot K^{-1}\right), h_{i}(r)$ is the thickness of the density layer within the anomaly (in $\mathrm{m}$ ), $T_{\sigma}(r)\left(S_{\sigma}(r)\right)$ is the vertically averaged temperature (salinity) at radial distance $r$ from the eddy center (in K (no unit)), and $T_{\sigma}(r e f)\left(S_{\sigma}(r e f)\right)$ is the vertically averaged temperature (salinity) in the same density layer outside the eddy (in K (no unit)). These estimates were then compared with the results for the meso-scale cold-core rings reported by Morrow et al. (2004). For the cold intrusion associated with Anomaly B1, we calculated AHA (ASA) for the density range of $26.5-27.2 \mathrm{~kg} \cdot \mathrm{m}^{-3}$ based on the temperature (salinity) deviation from the reference profile (Fig. 15). The AHA had a value of $-2.67 \times 10^{9} \mathrm{~J} \cdot \mathrm{m}^{-2}$, and the ASA had a value of $-133.9 \mathrm{~kg} \cdot \mathrm{m}^{-2}$. These values are comparable to those of the meso-scale cold-core rings. If these are integrated within a water column with $r$ of $8 \mathrm{~km}$, the total AHA is then $-5.4 \times 10^{17} \mathrm{~J}$ and ASA is $-2.7 \times 10^{10} \mathrm{~kg}$. Owing to the smallness of the anomaly, these values are substantially smaller than those for the cold-core rings $\left(-1.9 \times 10^{19} \mathrm{~J}\right.$ and $-8.2 \times 10^{11} \mathrm{~kg}$, respectively). However, if the small-scale anomalies are ubiquitous around the periphery of the meso-scale meander/eddy and integrated for the whole rim of the anomaly, the total AHA and ASA can be 20-fold greater than those for a single small-scale anomaly and are thus comparable to the values for a cold-core ring. The small-scale anomalies can also be integrated over the meandering or stable path for the larger domain. About seven of these meso-scale meanders can be located within an interval of $10^{\circ}$, while only two cold-core rings can be found in the same $10^{\circ}$ longitude between $140^{\circ}$ and $150^{\circ} \mathrm{E}$. Moreover, temporal development of the small-scale anomalies is usually much faster than that of meso-scale phenomena. The typical time-scale of shedding for cold-core rings is annual (Morrow et al., 2004). If the Eady-Charney time- 
scale for growth of baroclinic instability is assumed with a Richardson number of several hundreds, only 2-3 days are needed for its development. Hence, the typical frequency of development would be an order or two greater than that of the meso-scale eddies. Although there are large uncertainties in these spatial/temporal integrations, it is highly likely that the small-scale disturbances have a much greater role than that of meso-scale anomalies in meridional heat and freshwater exchange.

\section{Summary and conclusions}

High-resolution XCTD and XBT observations were conducted to study small-scale eddy variability in the SAF and its possible impact on the properties of the SAMW. Coarseresolution data from previous WOCE observations were also examined to reveal the water mass properties of SAMW varieties.

Small-scale features were clearly detected in the SAF region for all the three highresolution sections from west to east. Fluctuation of the $7^{\circ} \mathrm{C}$ isotherm was detected at a depth of $300-600 \mathrm{~m}$ on the $\sigma_{\theta}=26.8-26.9 \mathrm{~kg} \cdot \mathrm{m}^{-3}$ surface. Fluctuation of the $5^{\circ} \mathrm{C}$ isotherm was also found along the $140^{\circ} \mathrm{E}$ line. Temperature and salinity inversions of a similar spatial scale were identified on the same density surface. In $\theta-S$ diagrams, these small-scale fluctuations constitute cold/fresh intrusions. The intrusions were found on the line connecting the deeper SAMW at the lower latitudes and the shallower AASW at the higher latitudes, just beneath the seasonal mixed-layer. From the WOCE observations, the presence of SAMW with high DO was detected near the SAF, as reported by Rintoul and Bullister (1999). Immediately poleward of the SAF core, intrusions in $\theta-S$ diagrams with relatively high oxygen concentrations were found around the $7^{\circ} \mathrm{C}$ isotherm on the 26.8 $26.9 \mathrm{~kg} \cdot \mathrm{m}^{-3}$ surface, which were of nearly the same density as the small-scale anomalies 
and the high-DO SAMW. This implies that the small-scale anomalies contribute to the cross-frontal water exchange and to formation of high-DO SAMW.

The high-DO water was not the major SAMW component at least in a volumetric sense. However, it constitutes the base of the SAMW layer and forms the lower boundary of the SAMW. The relation between the total SAMW thickness and the role of the small-scale anomalies requires further study.

This study suggests a link between the relatively high-DO water beneath the wellmixed SAMW layer and small-scale disturbances in the core of the SAF. However, the high-resolution observations were only made for temperature and salinity, and the structure of oxygen-rich anomalies was not directly resolved. Moreover, observation was restricted to just one section for each opportunity, and the along-front structure and convergence/divergence in the small-scale eddies were not represented. To identify the detailed three-dimensional structure of these small-scale eddies, grid surveys using towed instruments with oxygen sensors are most suitable and will be required for forthcoming observations.

It is suggested that the cross-frontal water mass exchange by small-scale eddies can affect SAMW properties. However, the present GCM does not explicitly resolve eddies of this scale. The Gent and McWilliams (1990) parameterization is usually adopted for representation of baroclinic instability, but is not normally used for this scale range. Further studies on subgrid-scale parameterization will be needed to thoroughly reproduce the realistic formation process of the mode water in this ocean sector.

\section{Acknowledgments.}


The high-resolution XCTD/XBT observations were possible with the aid of a number of researchers and crew members. The observations aboard R/V Tangaroa were conducted by T. Sato, S. Watanabe, G. Hashida, H. Suzuki, T. Nishida, S. Kawaguchi, and S. Kudoh. The authors are grateful to the cruise leader, T. Odate, and the captain, A. Leachman, and his crew on board R/V Tangaroa. The observations aboard R/V Mirai were conducted by S. Okumura, N. Nagahama, R. Kimura, and N. Fujii. We would like to express our thanks to S. Takahashi, R. Kurihara, and N. Morioka for their support during the operation. We are most grateful to the cruise leader, S. Watanabe, and the captain, S. Akamine, and his crew on board R/V Mirai. Thanks are extended for critical reading of the original manuscript and constructive comments by the editor and three anonymous reviewers, which improved the manuscript substantially.

The ADT products were produced by the CLS Space Oceanography Division as part of the Environment and Climate EU ENACT project (EVK2-CT2001-00117) and with support from CNES.

These observations were partly conducted under the auspices of the Japanese Antarctic Research Expedition. This study was partly supported by Project for Sustainable Coexistence of Human, Nature, and the Earth (Research Revolution 2002) of the MEXT of the Japanese Government. This study was also supported by a Grant-in-Aid for Scientific Research (15710001) from the MEXT.

\section{References}

Aoki, S., 2006. XCTD/CTD comparison test for Antarctic oceanography. Journal of Oceanography, submitted. 
Aoki, S., Sato, T., 2004. JARE43 Tangaroa Marine Science Cruise Report (Physical Oceanography). Nankyoku Shiryo (Antarctic Record) 48, 204-218.

Belkin, I.M., Gordon, A.L., 1996. Southern Ocean fronts from the Greenwich meridian to Tasmania. Journal of Geophysical Research 101, 3675-3696.

de Szoeke, R.A., Levine, M.D., 1981. The advective flux of heat by mean geostrophic motions in the Southern Ocean. Deep-Sea Research 28, 1057-1085.

Ducet, N., Le Traon, P.Y., Reverding, G., 2000. Global high resolution mapping of ocean circulation from TOPEX/POSEIDON and ERS-1/2. Journal of Geophysical Research $105,19,477-19,498$.

Gent, P.R., McWilliams, J.C., 1990. Isopycnal mixing in ocean circulation models. Journal of Physical Oceanography 20, 150-155.

Gill, A.E., Green, J.S.A., Simmons, A.J., 1974. Energy partition in the large-scale ocean circulation and the production of mid-ocean eddies. Deep-Sea Research 21, 499-528.

Hofmann, E. E., 1985. The large-scale horizontal structure of the Antarctic Circumpolar Current from FGGE drifters. Journal of Geophysical Research 90, 7087-7097.

Joyce, T.M., Patterson, S.L., Millard Jr., R.C., 1981. Anatomy of a cyclonic ring in the Drake Passage. Deep-Sea Research 28A, 1265-1287.

McCartney, M.S., 1977. Subantarctic Mode Water. In: Angel, M. (Ed.), A voyage of Discovery, George Deacon 70th anniversary volume. Pergamon Press, Oxford, pp. 103119.

McCartney, M.S., 1982. The subtropical circulation of Mode Waters. Journal of Marine Research 40 (suppl.), 427-464. 
Morrow, R., Coleman, R., Church, J.A., Chelton, D.B., 1994. Surface eddy momentum flux and velocity variances in the Southern Ocean from Geosat altimetry. Journal of Physical Oceanography, 24, 2050-2071.

Morrow, R., Donguy, J.R., Chaigneau, A., Rintoul, S.R., 2004. Cold-core anomalies at the subantarctic front, south of Tasmania. Deep-Sea Research I 51, 1417-1440.

Nagata, Y., Michida, Y., Umimura, Y., 1988. Variations of positions and structures of the ocean fronts in the Indian Ocean sector of the Southern Ocean in the period from 1965 to 1987. In: Salirhage, D. (Ed.), Antarctic Ocean and Resources Variability. Springer, Berlin, pp. 92-98.

Orsi, A.H., Whitworth, T., Nowlin, W.D., 1995. On the meridional extent and fronts of the Antarctic Circumpolar Current. Deep-Sea Research I 42, 641-673.

Phillips, N.A., 1954. Energy transformations and meridional circulations associated with simple baroclinic waves in a two-level, quasi-geostrophic model. Tellus 6, 273-286.

Phillips, H.E., Rintoul, S.R., 2002. A mean synoptic view of the Subantarctic Front south of Australia. Journal of Physical Oceanography 32, 1536-1553.

Piola, A., Georgi, D.T., 1982. Circumpolar properties of Antarctic Intermediate Water and Subantarctic Mode Water. Deep-Sea Research 29, 687-711.

Pollard, R.T., Regier, L., 1992. Vorticity and vertical circulation at on ocean front. Journal of Physical Oceanography 22, 609-625.

Rintoul, S.R., Bullister, J.L., 1999. A late winter hydrographic section from Tasmania to Antarctica. Deep-Sea Research I 46, 1417-1454.

Rintoul, S.R., England, M., 2002. Ekman transport dominates air-sea fluxes in driving variability of Subantarctic Mode Water. Journal of Physical Oceanography 32, 1308- 
1321.

Rio M.-H., Hernandez, F., 2004. A mean dynamic topography computed over the world ocean from altimetry, in situ measurements, and a geoid model. Journal of Geophysical Research 109, C12032, doi:10.1029/2003JC002226.

Ruddick, B., 1992. Intrusive mixing in a Mediterranean salt lens - intrusion slopes and dynamical mechanisms. Journal of Physical Oceanography 22, 1274-1285.

Sallée, J., Wienders, N., Speer, K., Morrow, R., 2006. Formation of subantarctic mode water in the southeastern Indian Ocean. Ocean Dynamics, doi10.1007/s10236-005-0054$\mathrm{x}, 1-18$.

Sokolov, S., Rintoul, S.R., 2002. Structure of Southern Ocean fronts at $140^{\circ}$ E . Journal of Marine Systems 37, 151-184.

Sparrow, M.D., Heywood, K., Brown, J., Stevens, D.P., 1996. Current structure of the South Indian Ocean. Journal of Geophysical Research 101, 6377-6392.

Thompson, R.O.R.Y., Edwards, R.J., 1981. Mixing and water-mass formation in the Australian Subantarctic. Journal of Physical Oceanography 11, 1399-1406.

Wong, A.P.S., 2005. Subantarctic Mode Water and Antarctic Intermediate Water in the South Indian Ocean based on profiling float data 2000-2004. Journal of Marine Research 63, 789-812.

Yoshikawa, Y., Akitomo, K., Awaji, T., 2001. Formation process of intermediate water in baroclinic current under cooling. Journal of Geophysical Research 106, 1033-1051.

Yuan, X., Martinson, D.G., Dong, Z., 2004. Upper ocean thermohaline structure and its temporal variability in the southeast Indian Ocean. Deep-Sea Research I 51, 333-347. 


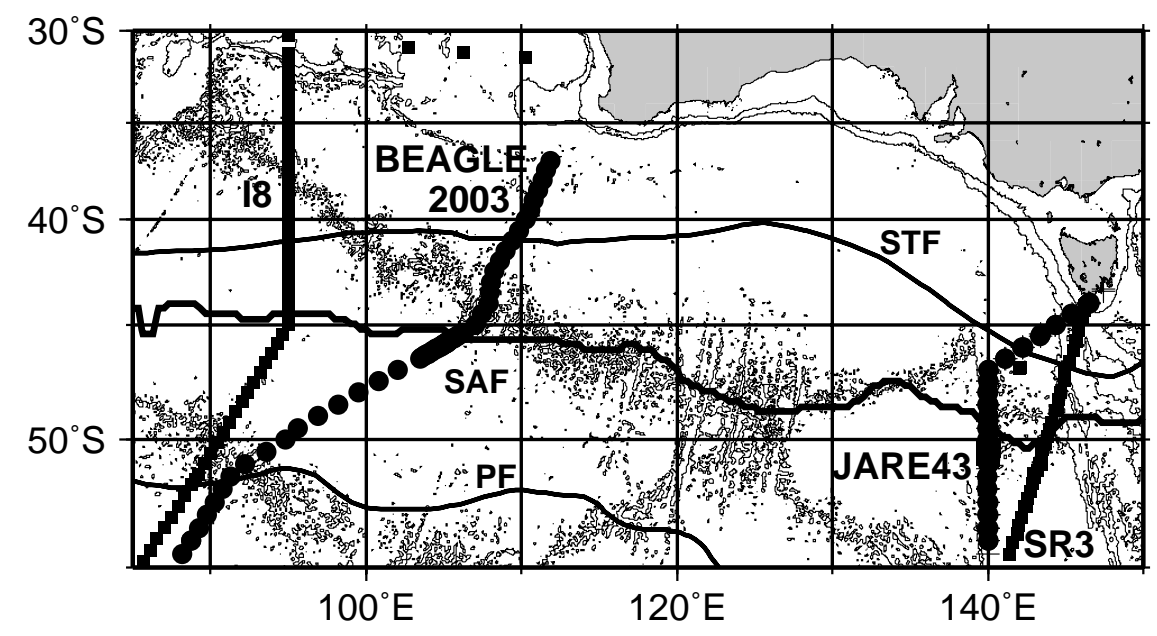

Figure 1. Study area in the Southern Ocean south of Australia. Dots denote locations of the BEAGLE2003 and JARE43 XCTD observations, and squares denote stations along I8 and SR3 lines of the WOCE Hydrographic Program. The Subantarctic Front (SAF) was defined as the 1.4-m contour of mean dynamic topography (Rio and Hernandez, 2004). The Subtropical Front (STF) and Polar Front (PF) are as defined by Orsi et al. (1995). 


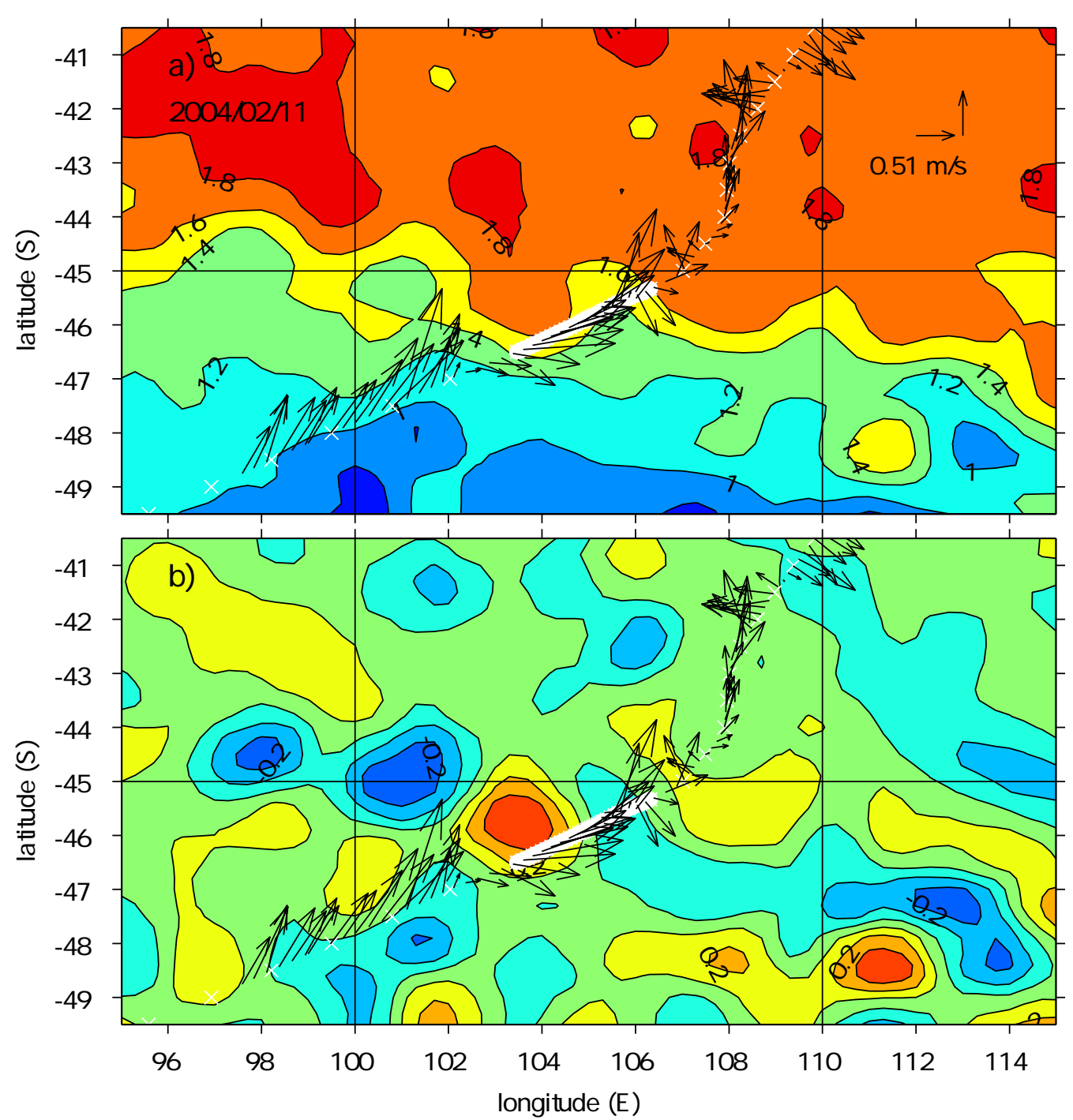

Figure 2. Distribution of a) absolute dynamic topography and b) sea level anomaly (in m) on February 11, 2004 for the western region around $105^{\circ} \mathrm{E}$. Crosses denote the XCTD/XBT observational positions of the BEAGLE2003 cruise and arrows denote the observed surface velocity vectors. 

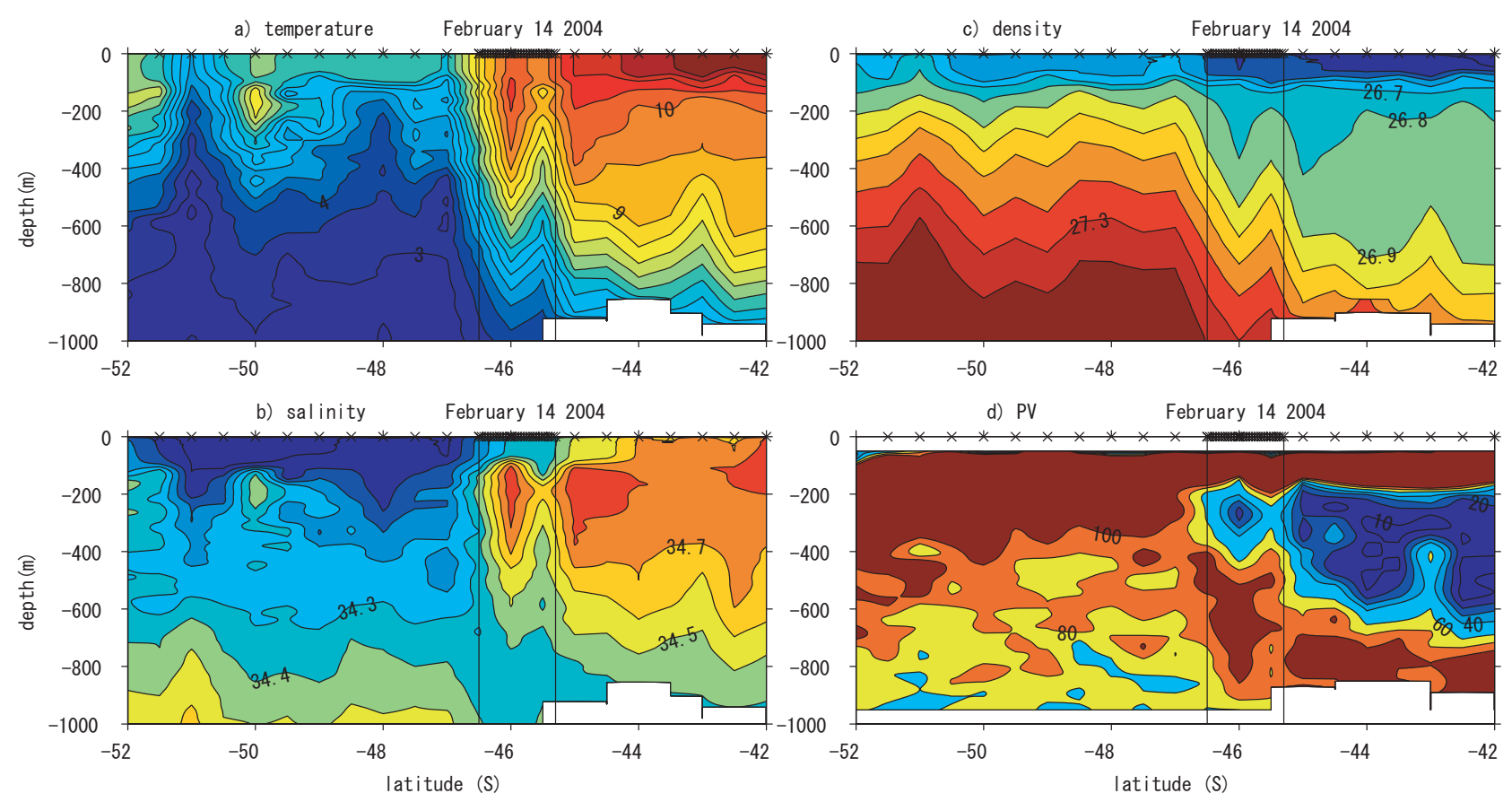

Figure 3. Profiles of a) temperature $\left({ }^{\circ} \mathrm{C}\right)$, b) salinity, c) potential density $\left(\sigma_{\theta} ; \mathrm{kg} \cdot \mathrm{m}^{-3}\right)$, and d) potential vorticity (PVU; $1 \mathrm{PVU}=10^{-14} \mathrm{~cm}^{-1} \cdot \mathrm{s}^{-1}$ ) of the BEAGLE 2003 transect. Crosses denote the observational positions. The area enclosed by solid lines indicates the region of intensive observations. The blank indicates the region with no data. 

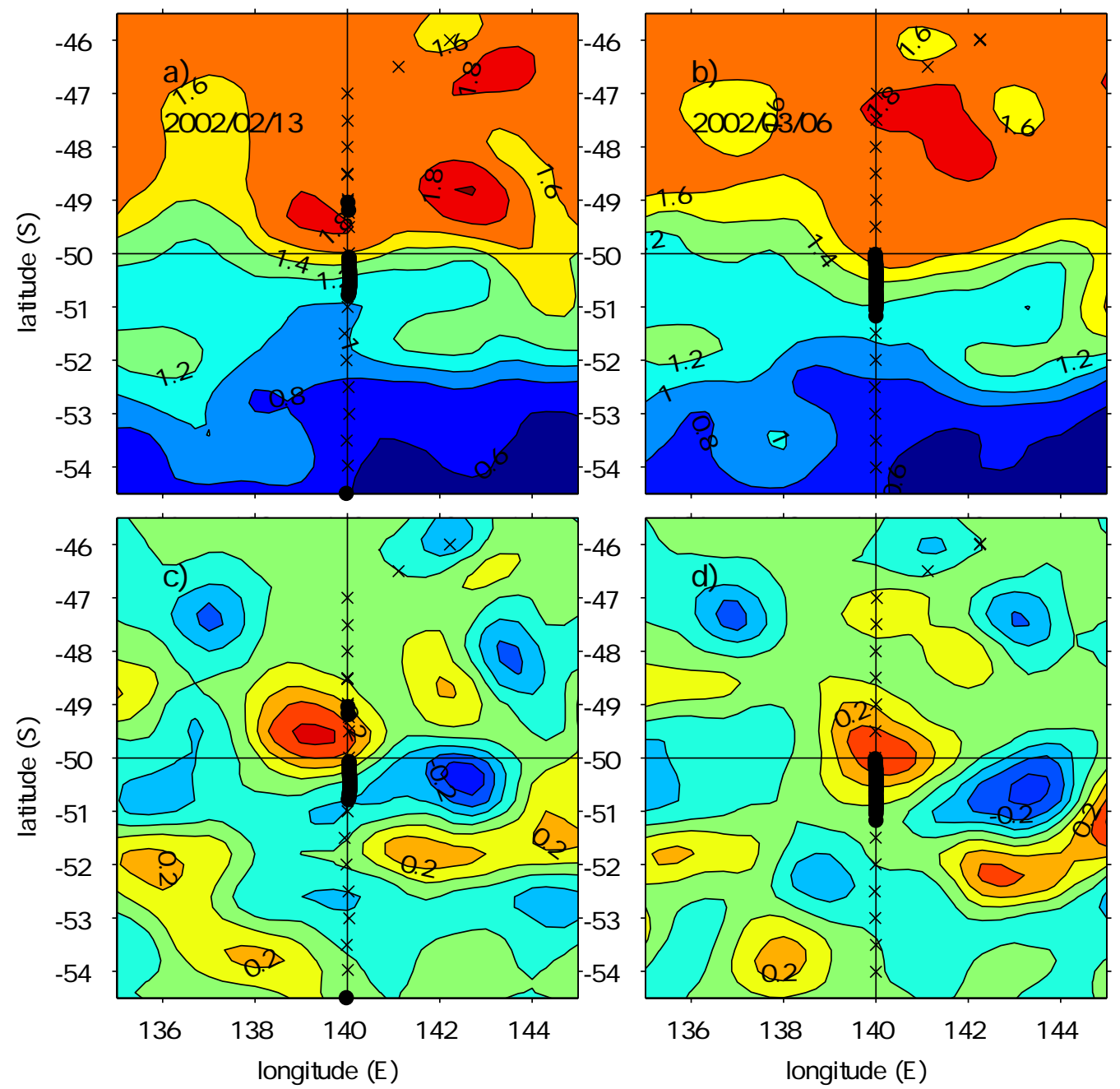

Figure 4. Distribution of the absolute dynamic topography and sea level anomaly (in $\mathrm{m}$ ) on a) and c) February 13, 2002 (southbound leg of JARE43) and b) and d) March 6, 2002 (northbound leg of JARE43) for the eastern region around $140^{\circ} \mathrm{E}$. Crosses denote the XCTD observations and dots denote the XBT observations. 

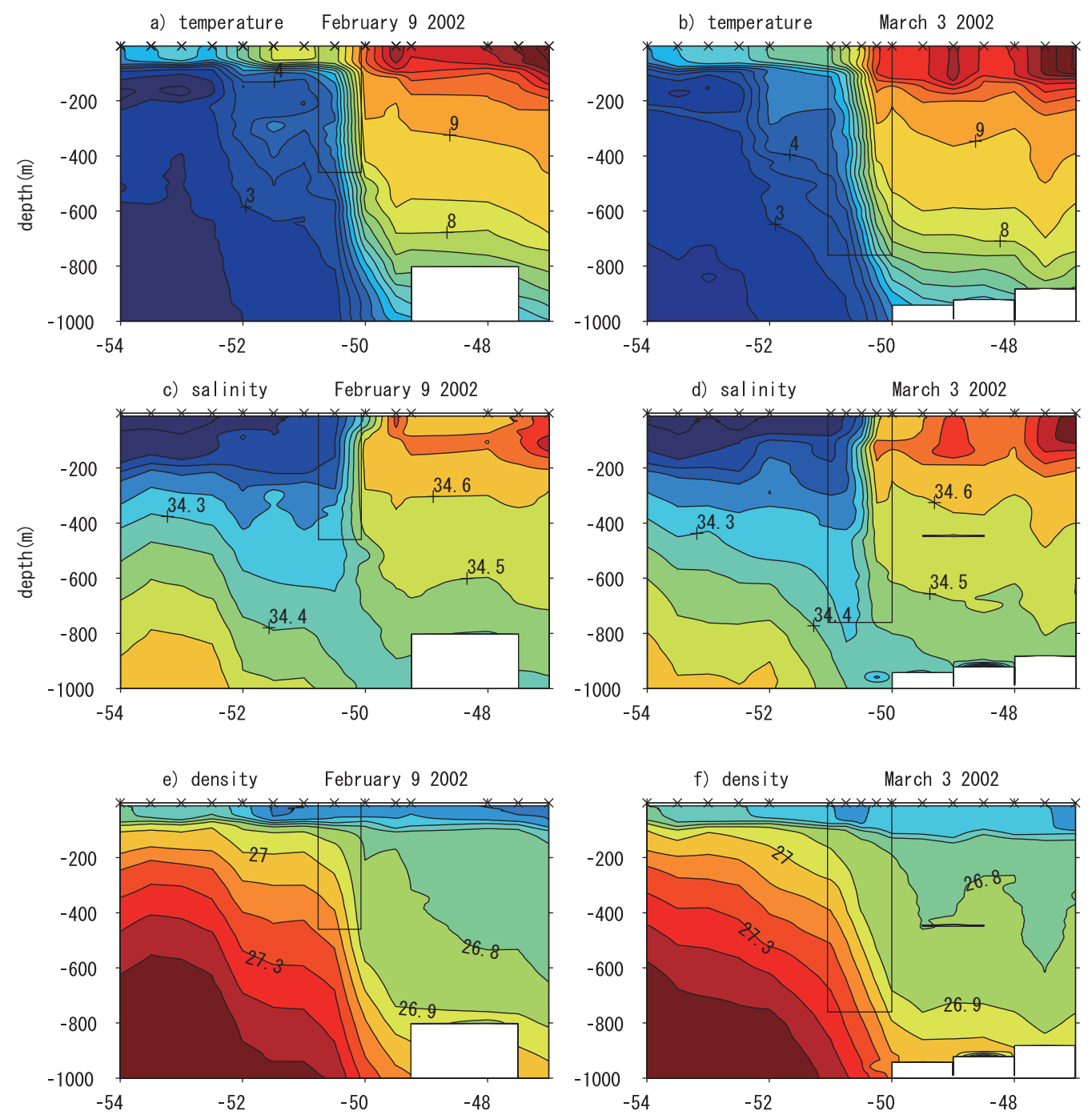

g) PV February 92002
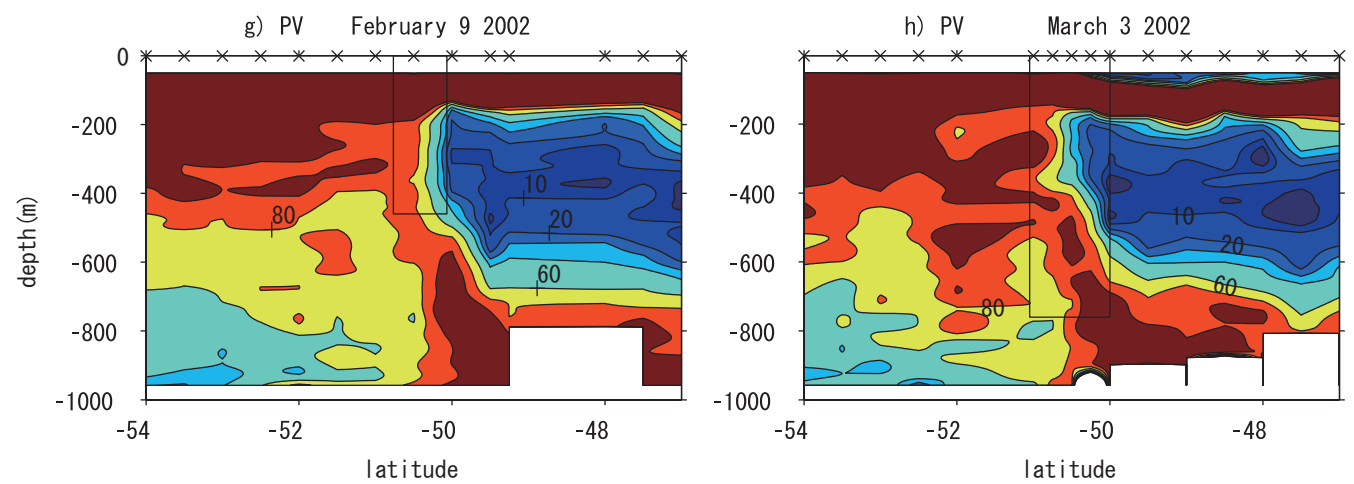

Figure 5. Profiles of a) and b) temperature $\left({ }^{\circ} \mathrm{C}\right)$, c) and d) salinity, e) and f) potential density $\left(\sigma_{\theta} ; \mathrm{kg} \cdot \mathrm{m}^{-3}\right)$, and $\left.\mathrm{g}\right)$ and $\left.\mathrm{h}\right)$ potential vorticity $\left(\mathrm{PVU} ; 1 \mathrm{PVU}=10^{-14} \mathrm{~cm}^{-1} \cdot \mathrm{s}^{-1}\right.$ ) on February 9 and March 3 of the JARE 43 transect along $140^{\circ} \mathrm{E}$. Crosses on top of the panels denote the observational positions. The area enclosed by solid lines indicates the region of intensive observations. The blank indicates the region with no data.
D R A F T
November 29, 2006, 9:37am

D R A F T 


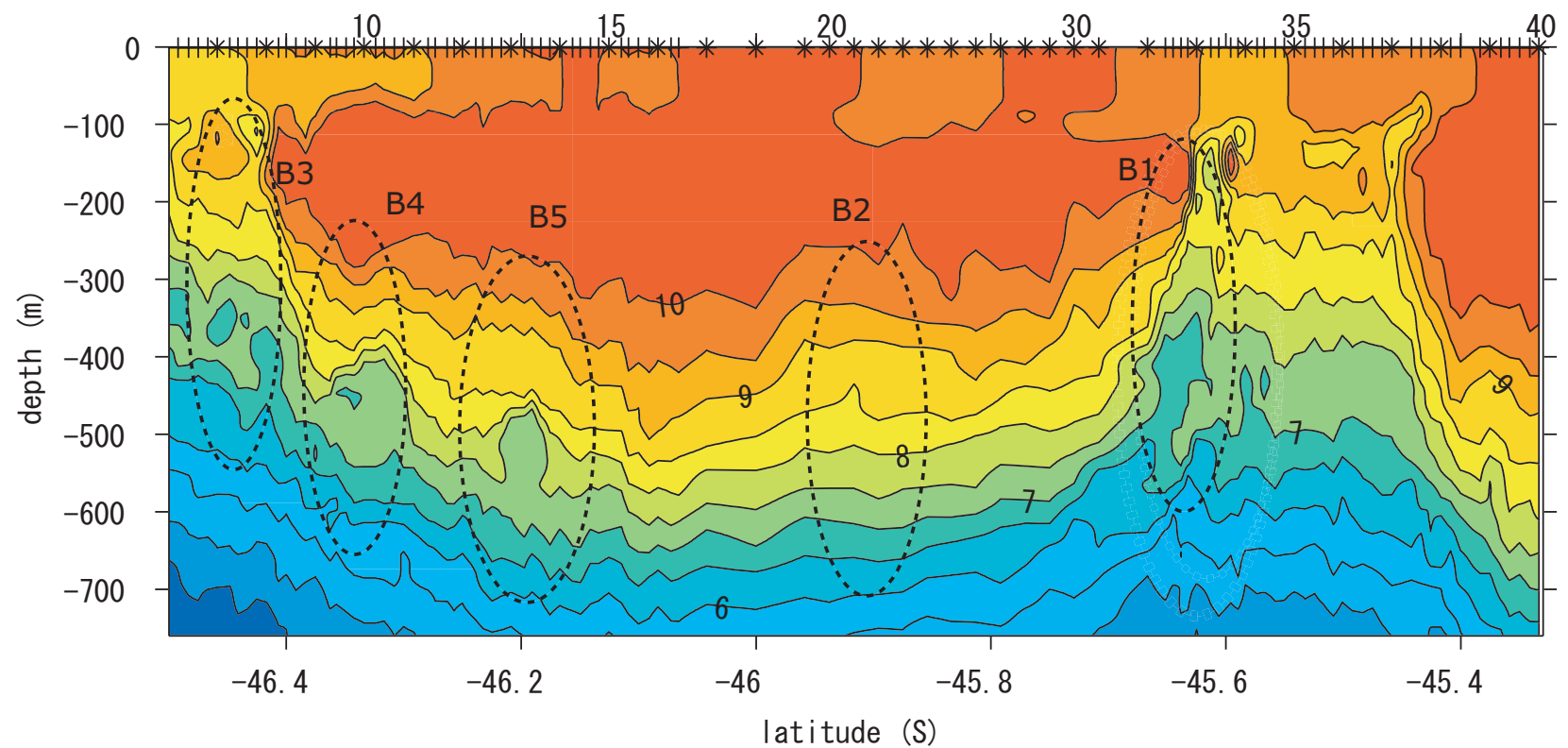

Figure 6. High-resolution temperature profile $\left(\right.$ in $\left.{ }^{\circ} \mathrm{C}\right)$ of the BEAGLE2003 transect derived with XCTD and XBT observations. Anomalous features are enclosed by broken ovals. Crosses denote the positions of XCTD stations, and bars denote the XBT observations. The numbers on the top indicate the XCTD station numbers. The contour interval is $0.5{ }^{\circ} \mathrm{C}$. 

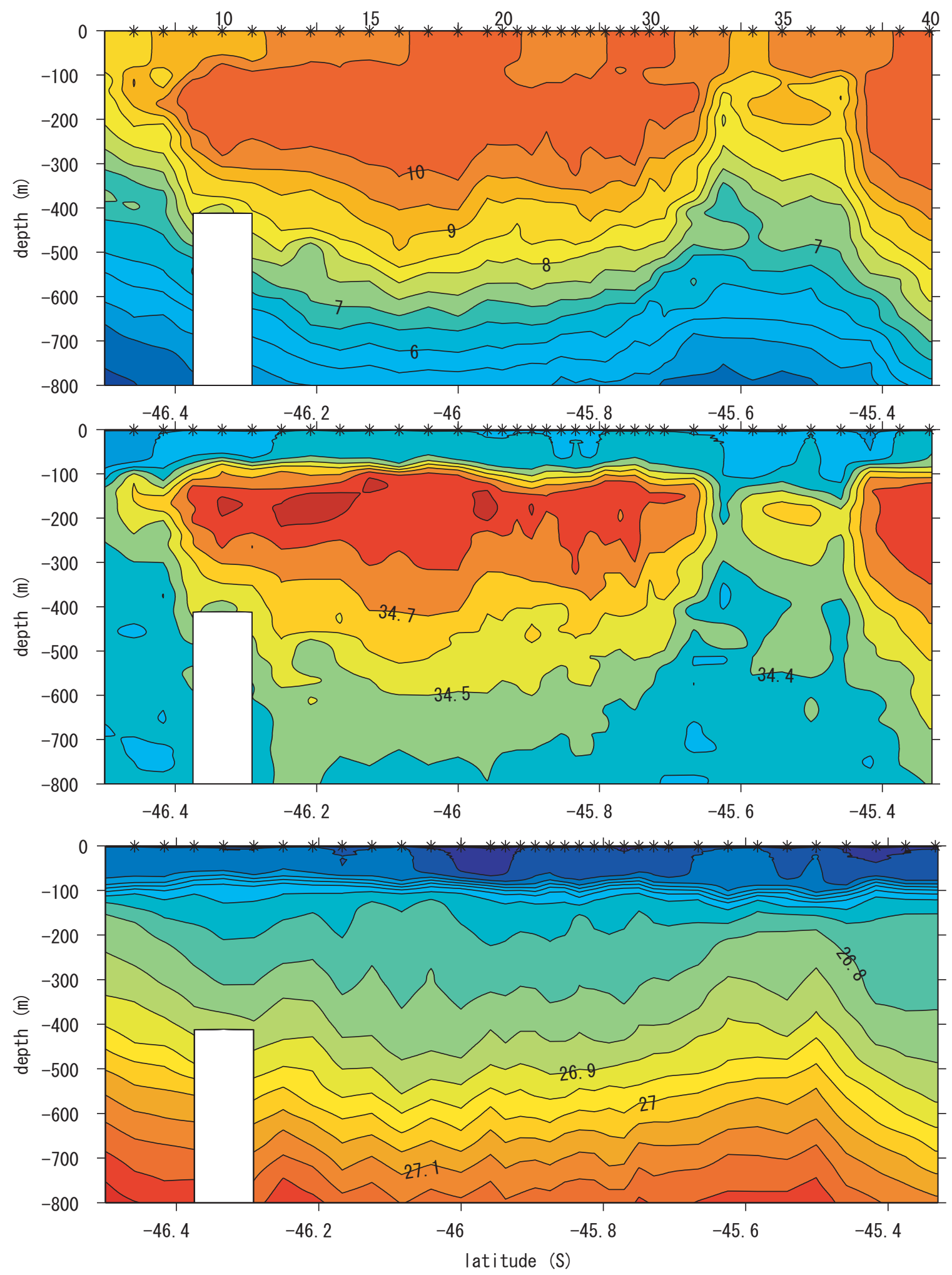

Figure 7. Temperature $\left({ }^{\circ} \mathrm{C}\right.$; top), salinity (middle) and potential density $\left(\sigma_{\theta}\right.$ in $\mathrm{kg} \cdot \mathrm{m}^{-3}$; bottom) profiles of the BEAGLE2003 transect derived with XCTD. Crosses denote the positions of XCTD stations, and the numbers indicate the station numbers. The blank indicates the region with no data.

D R A F T

November 29, 2006, 9:37am

D R A F T 
a)

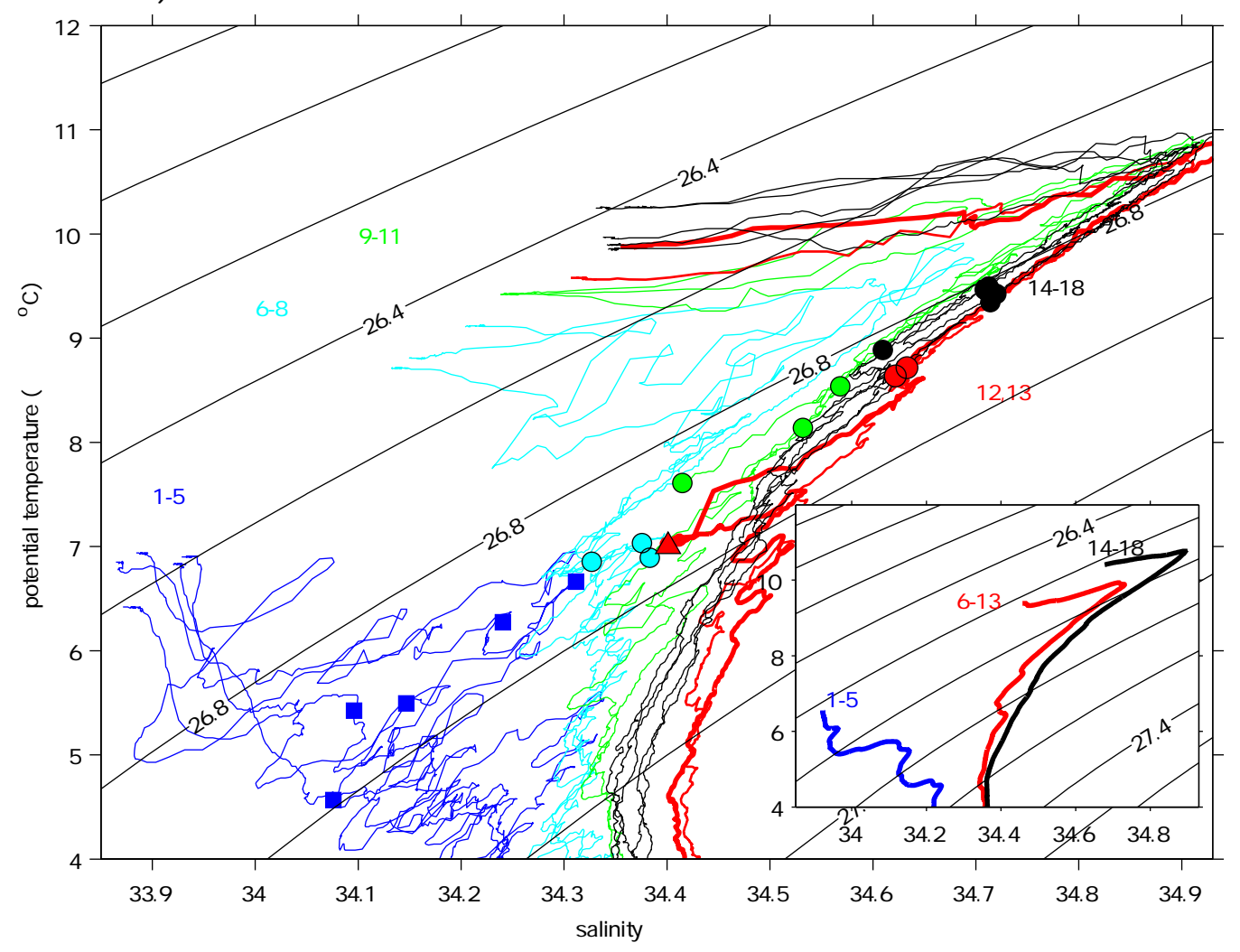

b)

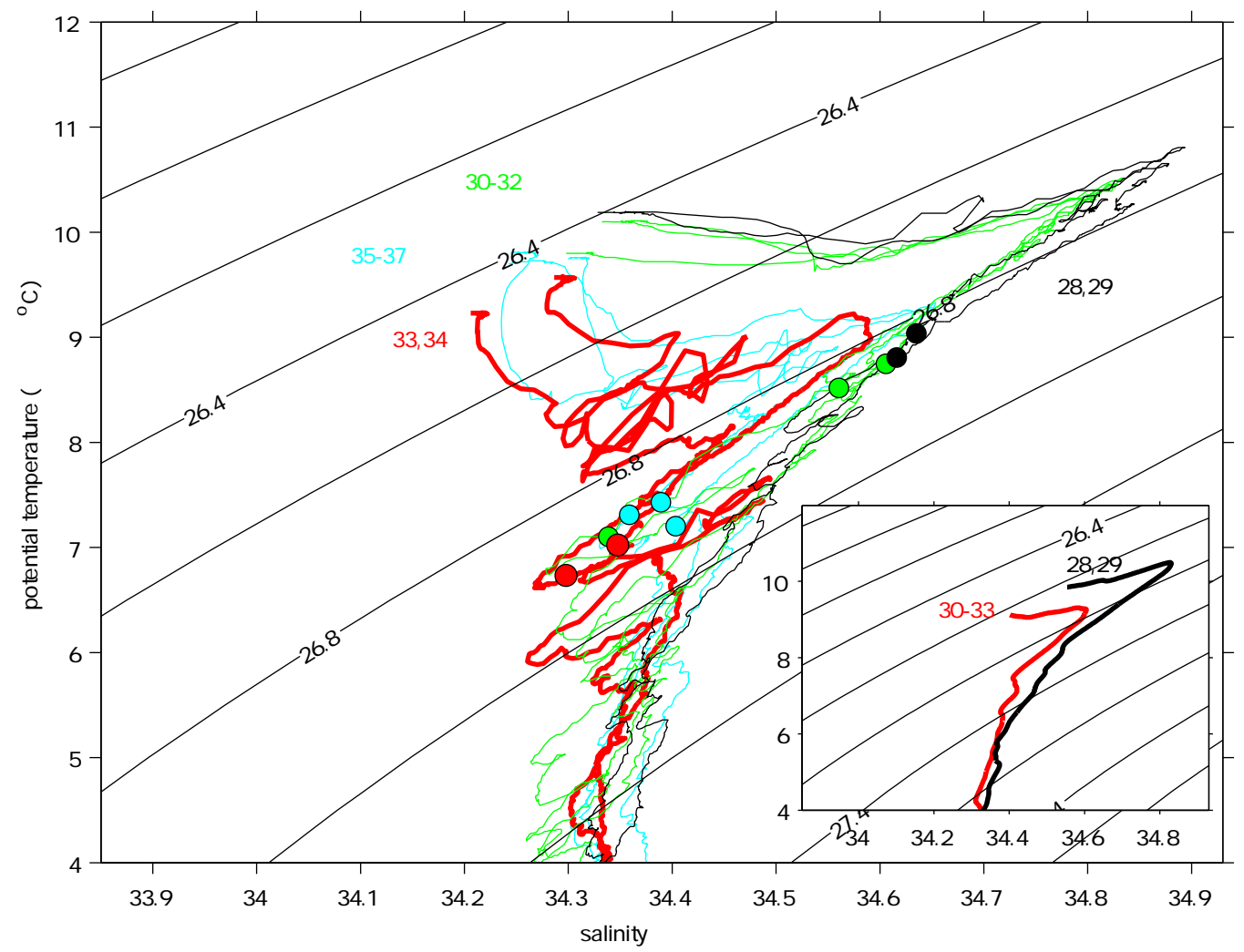


Figure 8. Potential temperature-salinity $(\theta-S)$ diagram for a) the southern flank (49.5-46.0 $\circ \mathrm{S})$ and b) the northern flank (45.75-45.46 ${ }^{\circ} \mathrm{S}$ ) of the meandering SAF, derived with the BEAGLE2003 XCTDs. The numbers denote the XCTD station number, which are shown on the top of Fig. 7. Dots (squares) denote the $\theta-S$ properties at a depth of $400 \mathrm{~m}(200 \mathrm{~m})$. Red triangle denotes that at depth of $500 \mathrm{~m}$ at station 13. Lines in a) denote the $\theta-S$ curves in blue for stations 1-5, cyan for 6-8, green for 9-11, red for 12-13, and black for 14-18. The lines in the inset show the average on the density surface in blue for stations $1-5$, red for $6-13$, and black for $14-18$. The lines in b) denote the $\theta-S$ curves in black for stations $28-29$, green for $30-32$, red for 33-34, and cyan for 35-37. Lines in the inset show the average on the density surface in red for stations 30-33 and black for 28-29. 

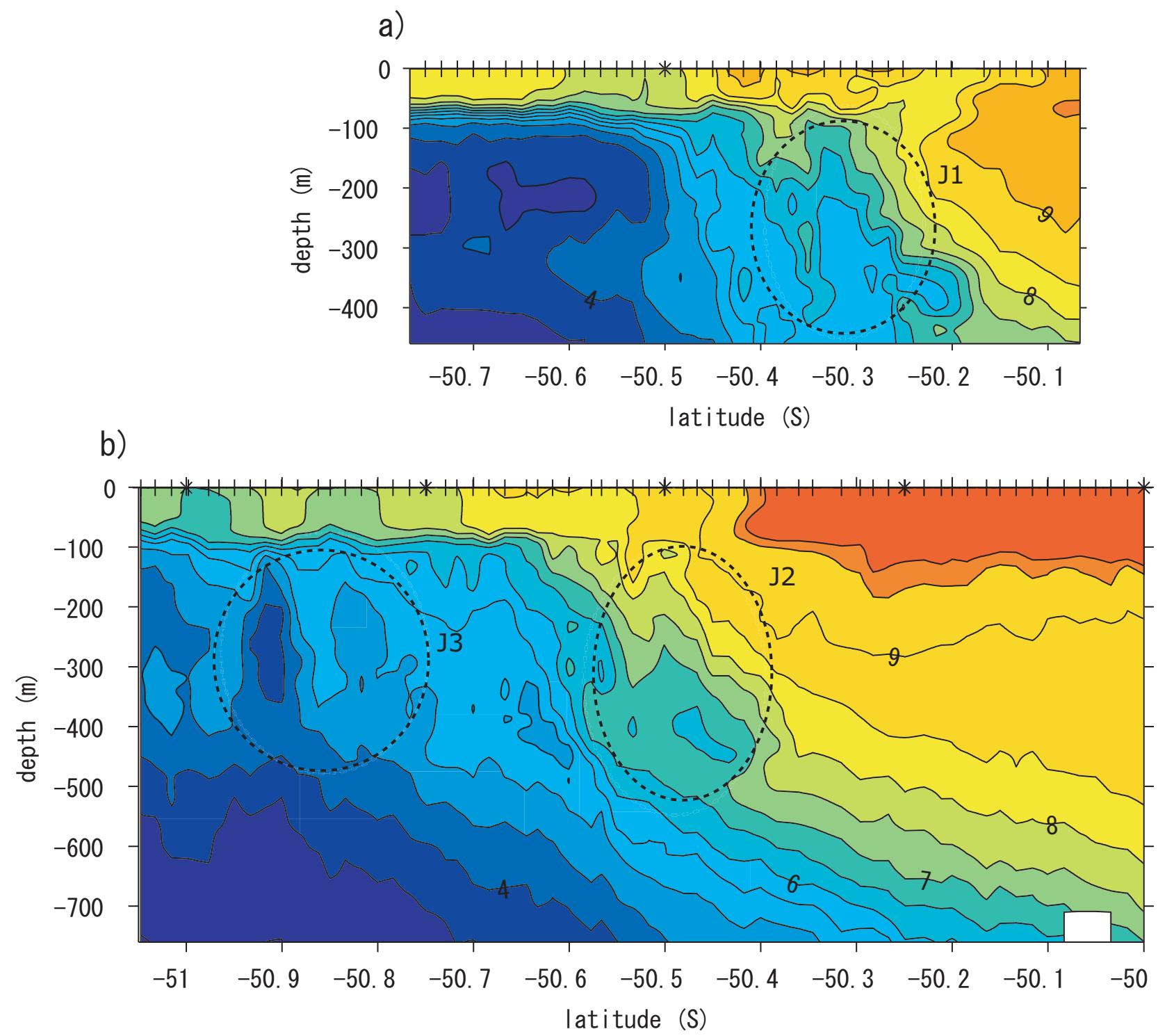

Figure 9. Temperature profiles (in ${ }^{\circ} \mathrm{C}$ ) of the JARE43 leg on a) 9 February and b) 3 March derived with XBT and XCTDs. Anomalous features are enclosed by broken ovals. Tick marks on the top indicate the XBT positions and crosses denote the XCTD stations. The contour interval is $0.5^{\circ} \mathrm{C}$. The blank indicates the region with no data. 


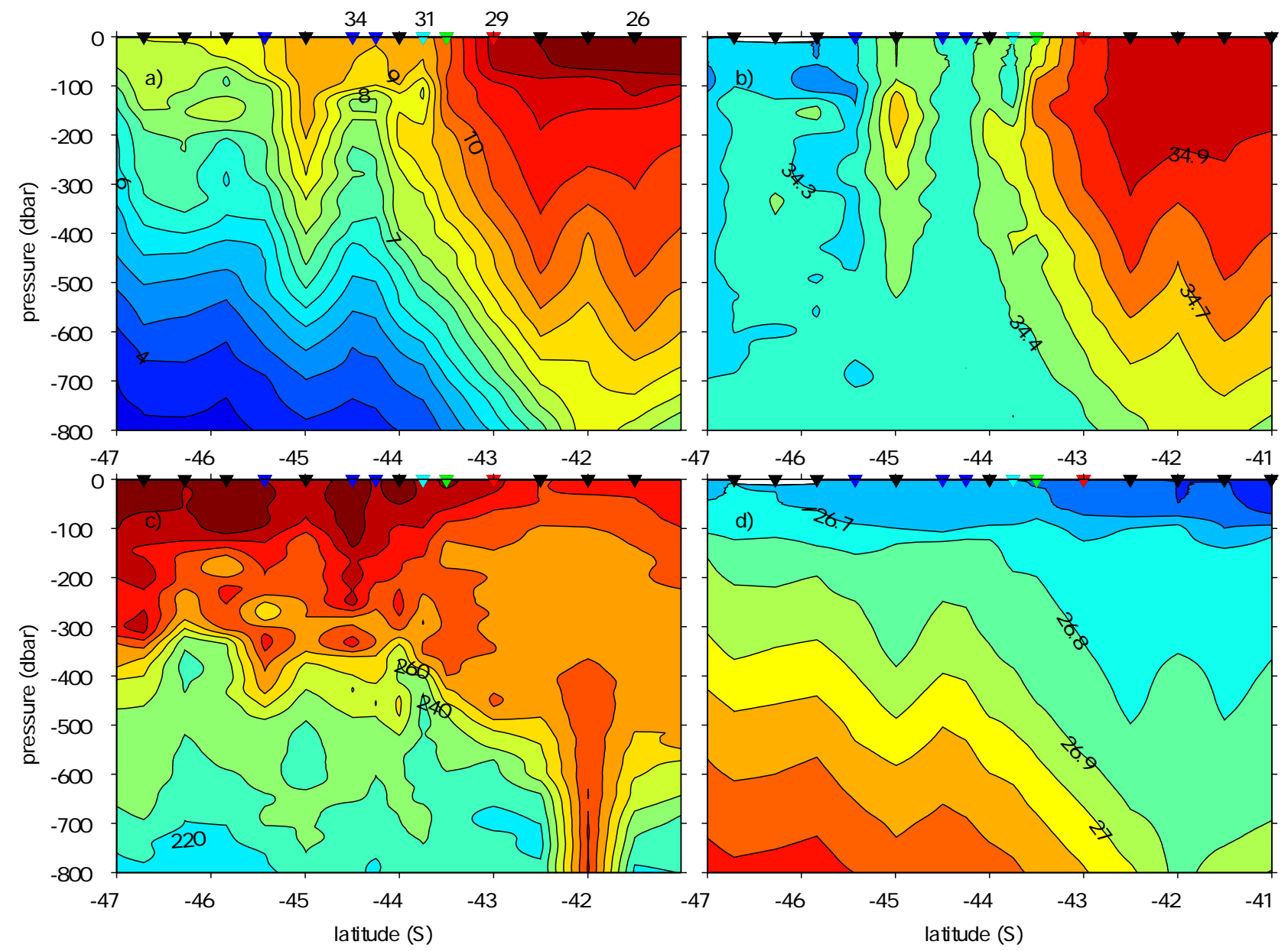

Figure 10. a) Potential temperature $\left({ }^{\circ} \mathrm{C}\right)$, b) salinity, c) dissolved oxygen $\left(\mu \mathrm{mol} \cdot \mathrm{kg}^{-1}\right)$, and d) potential density $\left(\sigma_{\theta} ; \mathrm{kg} \cdot \mathrm{m}^{-3}\right)$ sections for WOCE I8. Triangles on the top of the panels denote the observational positions, and numbers denote the station numbers. 

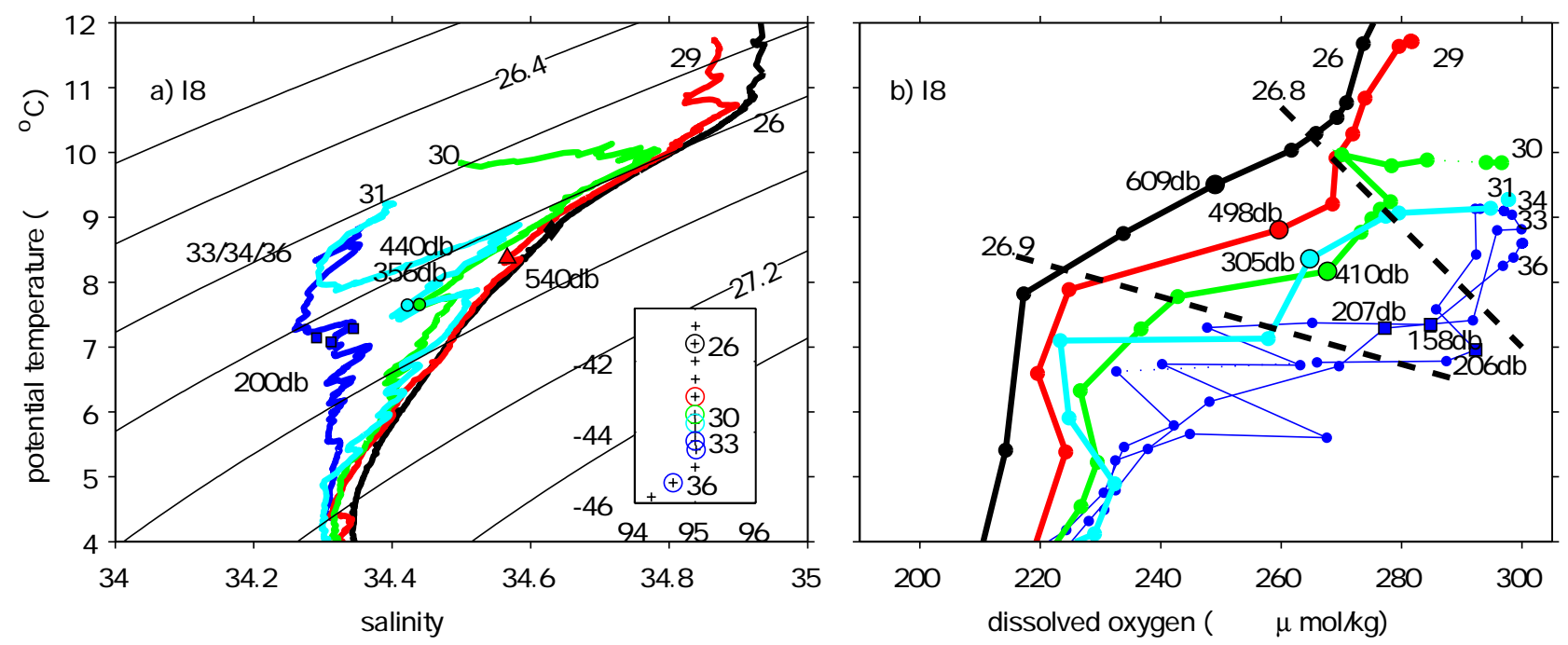

Figure 11. a) Potential temperature-salinity $(\theta-S)$ and b) potential temperature-dissolved oxygen $(\theta-\mathrm{DO})$ diagrams for WOCE I8 in December 1994. Each color of the $\theta-S(\theta-\mathrm{DO})$ curve corresponds to a different station shown in the enclosed panel for station locations (the numbers are the station numbers). Triangles denote the $\theta-S$ properties at the intrusions that were detected at the depths indicated nearby. Squares (dots) represent shallow levels around 200 dbar (deep levels around 400-500 dbar). Broken lines in b) denote the approximate density contours for 26.8 and $26.9 \mathrm{~kg} \cdot \mathrm{m}^{-3}$, reconstructed from the property distribution in the panel. 

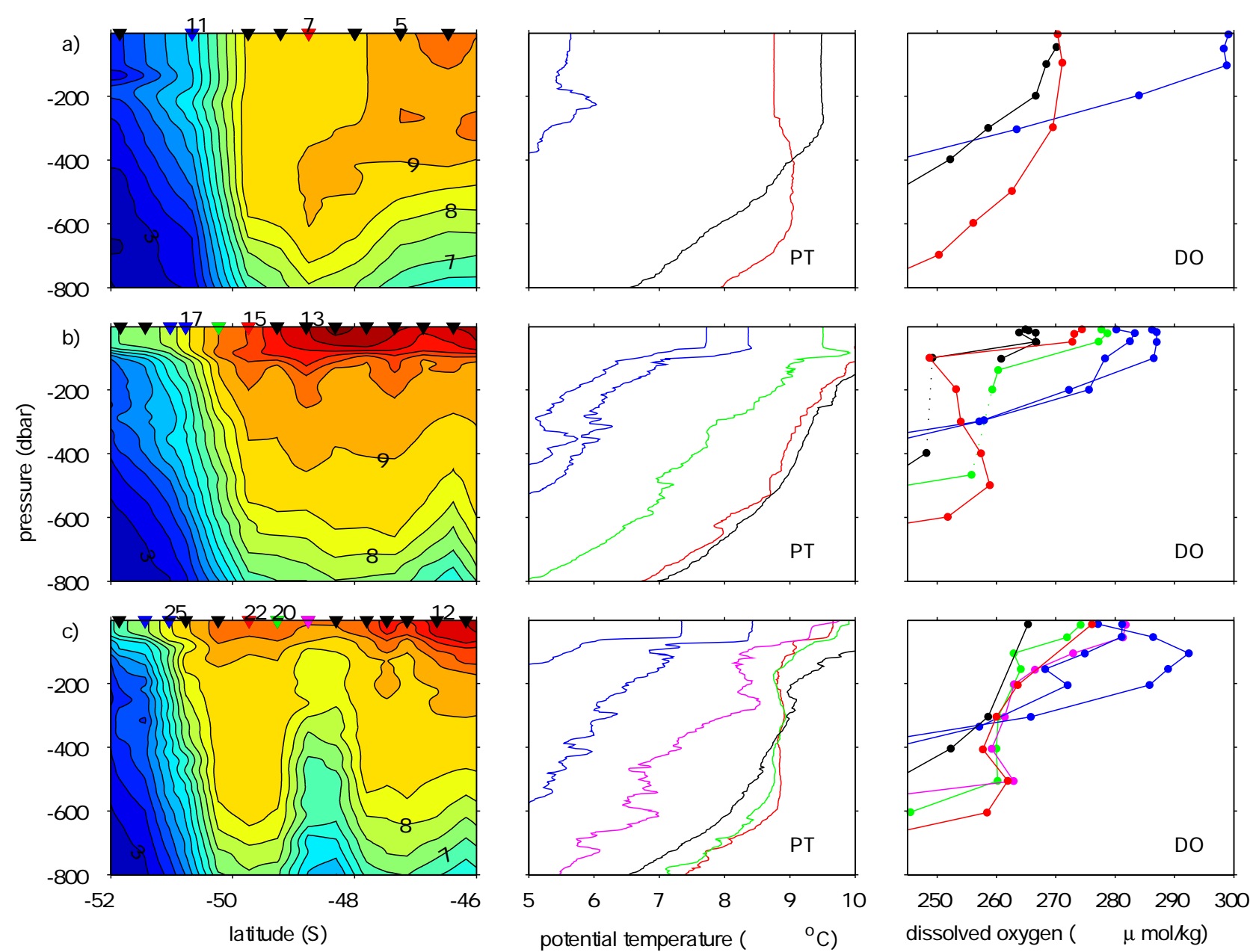

Figure 12. Potential temperature sections (left) across the SAF for WOCE SR3 in a) October 1991, b) March 1993, and c) January 1994, and vertical profiles of potential temperature $\left({ }^{\circ} \mathrm{C}\right.$; center) and dissolved oxygen $\left(\mu \mathrm{mol} \cdot \mathrm{kg}^{-1} ;\right.$ right $)$ at several stations indicated in the left panels. Triangles on the top of the left panels denote the observational positions, and numbers denote the station numbers. 

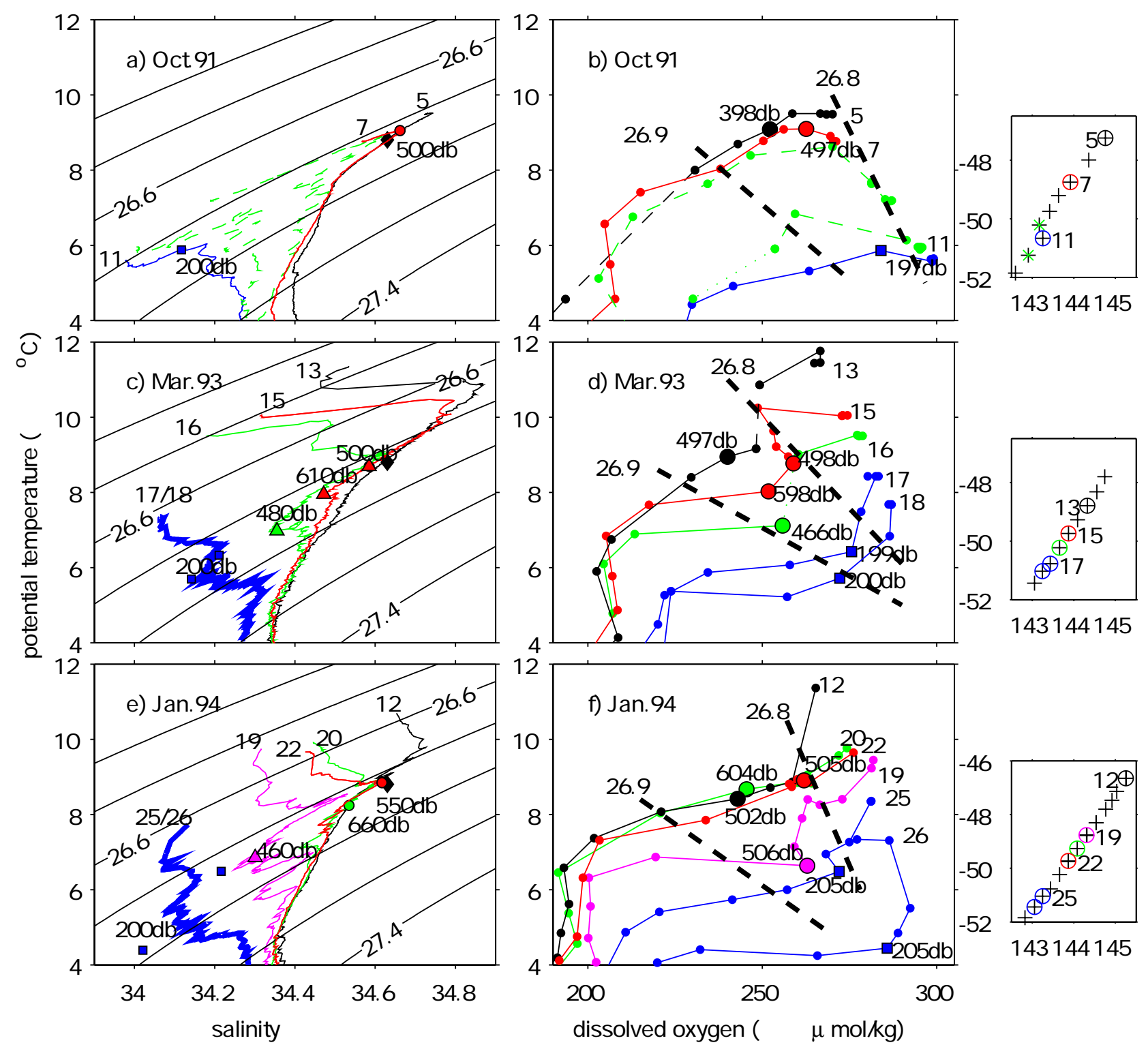

Figure 13. Potential temperature-salinity $(\theta-S)$ and potential temperature-dissolved oxygen ( $\theta$-DO) diagrams for a) and b) SR3 in October 1991, c) and d) SR3 in March 1993, and e) and f) SR3 in January 1994. Each color of the $\theta-S$ and $\theta-$ DO curves corresponds to a different station, shown in the right panels. Triangles denote the $\theta-S$ properties at the intrusions that were detected at the depths indicated nearby. Squares (dots) denote the $\theta-S$ and $\theta-D O$ properties at the shallow depths around 200 dbar (deep depths around 400-500 dbar); the depths are indicated by the numbers nearby. 

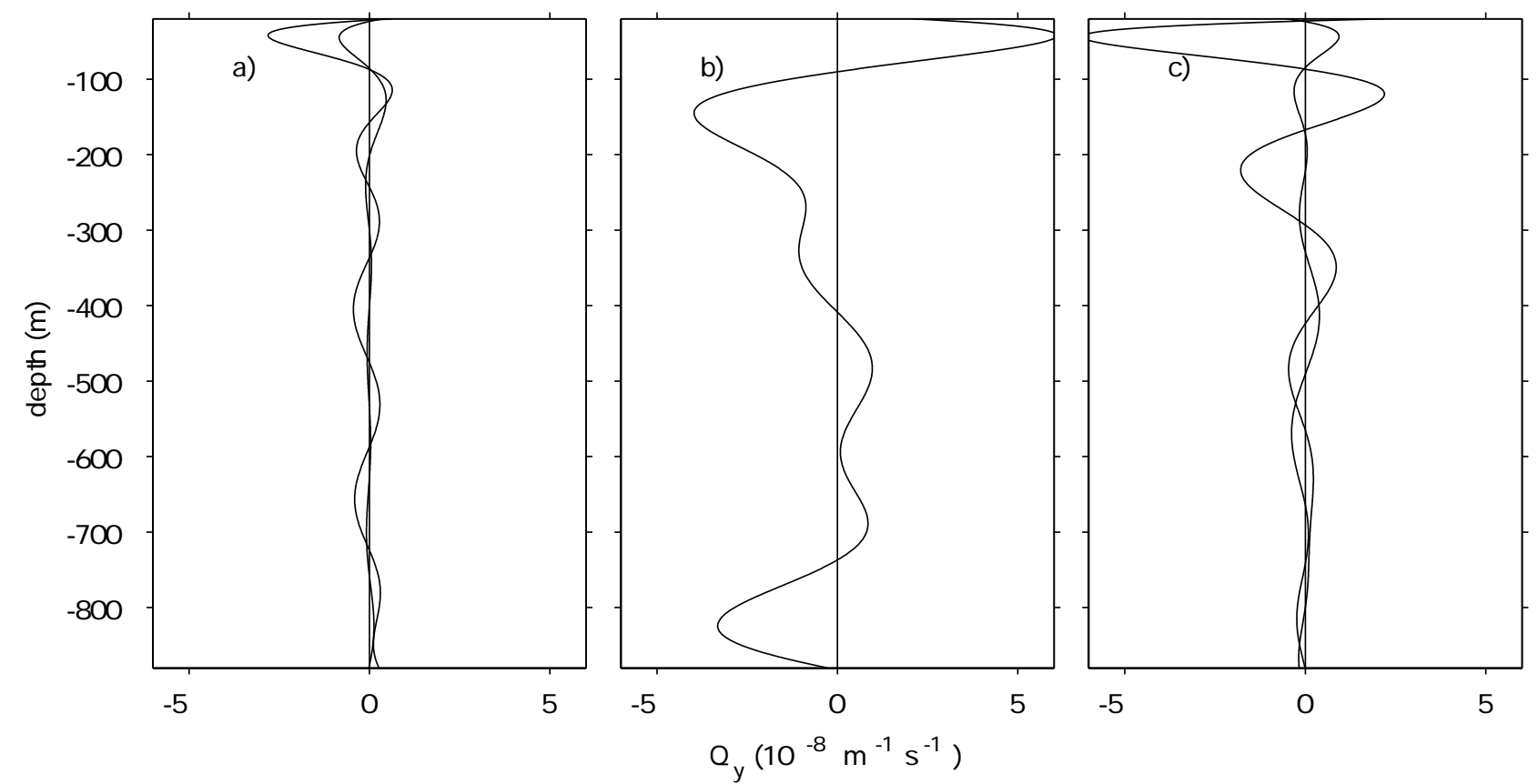

Figure 14. Vertical profile of $Q_{y}$, derived using Equation (1), for a) south of the SAF (49 ${ }^{\circ}$ $\mathrm{S}), \mathrm{b})$ in the center of the $\operatorname{SAF}\left(45.6^{\circ} \mathrm{S}\right)$, and c) north of the SAF $\left(42^{\circ} \mathrm{S}\right)$, derived for the BEAGLE2003 transect. 

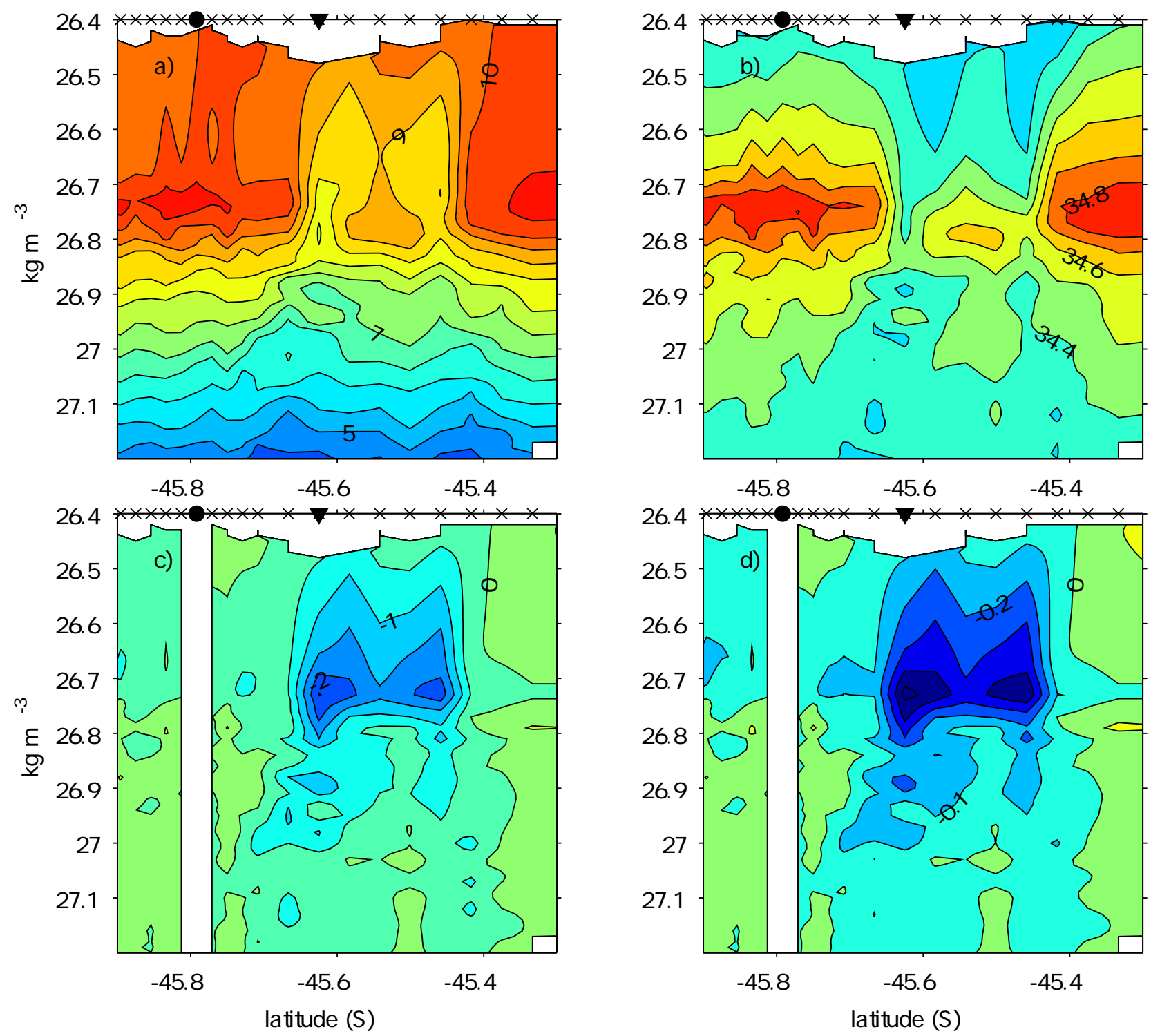

Figure 15. a) Temperature and b) salinity on density surfaces across the SAF axis, and c) and d) their departure from the reference profile for the BEAGLE2003 transect. The position of the reference point is indicated by dots. Available heat and salt anomalies were calculated for the anomaly indicated by triangles. Contour intervals are $0.5^{\circ} \mathrm{C}$ for a) and c) and 0.1 for b) and d). 